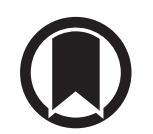

CrossMark

\title{
Global Strategy for the Diagnosis, Management, and Prevention of Chronic Obstructive Lung Disease 2017 Report: GOLD Executive Summary
}

\author{
Claus F. Vogelmeier ${ }^{1,21}$, Gerard J. Criner ${ }^{2,21}$, Fernando J. Martinez ${ }^{3,21}$, \\ Antonio Anzueto ${ }^{4}$, Peter J. Barnes ${ }^{5}$, Jean Bourbeau ${ }^{6}$, Bartolome R. Celli ${ }^{7}$, \\ Rongchang Chen ${ }^{8}$, Marc Decramer ${ }^{9}$, Leonardo M. Fabbri ${ }^{10}$, Peter Frith ${ }^{11}$, \\ David M.G. Halpin ${ }^{12}$, M. Victorina López Varela ${ }^{13}$, Masaharu Nishimura ${ }^{14}$, \\ Nicolas Roche ${ }^{15}$, Roberto Rodriguez-Roisin ${ }^{16}$, Don D. Sin ${ }^{17}$, Dave Singh ${ }^{18}$, \\ Robert Stockley ${ }^{19}$, Jørgen Vestbo ${ }^{18}$, Jadwiga A. Wedzicha ${ }^{5}$ and Alvar Agusti ${ }^{20}$
}

\begin{abstract}
Affiliations: ${ }^{1}$ University of Marburg, Member of the German Center for Lung Research (DZL), Marburg, Germany. ${ }^{2}$ Lewis Katz School of Medicine at Temple University, Philadelphia, PA, USA. ${ }^{3}$ New York Presbyterian Hospital, Weill Cornell Medical Center, New York, NY, USA. 'University of Texas Health Science Center and South Texas Veterans Health Care System, San Antonio, TX, USA. ${ }^{5}$ National Heart and Lung Institute, Imperial College, London, UK. ${ }^{6}$ McGill University Health Centre, McGill University, Montreal, Canada. ${ }^{7}$ Brigham and Women's Hospital, Boston, MA, USA. ${ }^{8}$ State Key Lab for Respiratory Disease, Guangzhou Institute of Respiratory Disease, First Affiliated Hospital of Guangzhou Medical University, Guangzhou, China. ${ }^{9}$ University of Leuven, Leuven, Belgium. ${ }^{10}$ University of Modena and Reggio Emilia, Modena, Italy. ${ }^{11}$ Flinders University Faculty of Medicine, Bedford Park, Australia. ${ }^{12}$ Royal Devon and Exeter Hospital, Exeter, UK. ${ }^{13}$ Universidad de la República, Hospital Maciel, Montevideo, Uruguay. ${ }^{14} \mathrm{Hokkaido}$ University School of Medicine, Sapporo, Japan. ${ }^{15}$ Hôpital Cochin (APHP), University Paris Descartes, Paris, France. ${ }^{16}$ Thorax Institute, Hospital Clinic Universitat de Barcelona, Barcelona, Spain. ${ }^{17}$ St Paul's Hospital, University of British Columbia, Vancouver, Canada. ${ }^{18}$ University of Manchester, Manchester, UK. ${ }^{19}$ University Hospital, Birmingham, UK. ${ }^{20}$ Hospital Clínic, Universitat de Barcelona, Ciberes, Barcelona, Spain. ${ }^{21}$ These authors contributed equally to the manuscript.
\end{abstract}

Correspondence: Claus F. Vogelmeier, Dept of Medicine, Pulmonary and Critical Care Medicine, University of Marburg, Baldingerstraße, 35043 Marburg, Germany. E-mail: claus.vogelmeierДmed.uni-marburg.de

@ERSpublications

Read the executive summary of the new @GOLD_COPD 2017 report in the European Respiratory Journal http://ow.ly/XxfD308BDfc

Cite this article as: Vogelmeier CF, Criner GJ, Martinez FJ, et al. Global Strategy for the Diagnosis, Management, and Prevention of Chronic Obstructive Lung Disease 2017 Report: GOLD Executive Summary. Eur Respir J 2017; 49: 1700214 [https://doi.org/10.1183/13993003.00214-2017].

ABSTRACT This Executive Summary of the Global Strategy for the Diagnosis, Management, and Prevention of COPD (GOLD) 2017 Report focuses primarily on the revised and novel parts of the document. The most significant changes include: 1) the assessment of chronic obstructive pulmonary disease has been refined to separate the spirometric assessment from symptom evaluation. ABCD groups are now proposed to be derived exclusively from patient symptoms and their history of exacerbations; 2) for each of the groups A to D, escalation strategies for pharmacological treatments are proposed; 3) the concept of de-escalation of therapy is introduced in the treatment assessment scheme; 4) nonpharmacologic therapies are comprehensively presented and; 5) the importance of comorbid conditions in managing COPD is reviewed.

This article has been amended according to the erratum published in the June 2017 issue of the European Respiratory Journal. This article has supplementary material available from erj.ersjournals.com Received: Jan 302017 | Accepted: Jan 302017

Conflict of interest: Disclosures can be found alongside this article at erj.ersjournals.com

Copyright (๑2017 the American Thoracic Society. Published with permission from the American Thoracic Society. Design and branding are copyright @ERS 2017. 


\section{Introduction}

This Executive Summary of the Global Strategy for the Diagnosis, Management, and Prevention of COPD (GOLD) 2017 Report is based on peer-reviewed publications to October 2016.

Levels of evidence are assigned to evidence-based recommendations where appropriate. Categories used to grade the levels of evidence are provided in table S1 in the supplementary material.

\section{Definition and factors that influence chronic obstructive pulmonary disease development and progression}

\section{Key points}

- Chronic obstructive pulmonary disease (COPD) is a common, preventable and treatable disease that is characterised by persistent respiratory symptoms and airflow limitation due to airway and/or alveolar abnormalities usually caused by significant exposure to noxious particles or gases.

- Dyspnoea, cough and/or sputum production are the most frequent symptoms; symptoms are commonly under-reported by patients.

- Tobacco smoking is the main risk exposure for COPD, but environmental exposures like biomass fuel exposure and air pollution may contribute. Besides exposures, host factors (genetic abnormalities, abnormal lung development and accelerated agingl predispose individuals to develop COPD.

- COPD may be punctuated by acute worsening of respiratory symptoms, called exacerbations.

- In most patients, COPD is associated with significant concomitant chronic diseases, which increase morbidity and mortality.

\section{Definition and pathogenesis}

COPD is a common, preventable and treatable disease that is characterised by persistent respiratory symptoms and airflow limitation that is due to airway and/or alveolar abnormalities usually caused by significant exposure to noxious particles or gases.

The chronic airflow limitation that characterises COPD is caused by a mixture of small airways disease (e.g., obstructive bronchiolitis) and parenchymal destruction (emphysema), the relative contributions of which vary from person to person. Chronic inflammation causes structural changes, small airways narrowing and destruction of lung parenchyma. A loss of small airways may contribute to airflow limitation and mucociliary dysfunction, a characteristic feature of the disease.

Chronic respiratory symptoms may precede the development of airflow limitation and be associated with acute respiratory events [1]. Chronic respiratory symptoms may exist in individuals with normal spirometry $[1,2]$ and a significant number of smokers without airflow limitation have structural evidence of lung disease manifested by the presence of emphysema, airway wall thickening and gas trapping $[1,2]$.

\section{Factors that influence disease development and progression}

Although cigarette smoking is the most well studied COPD risk factor, epidemiologic studies demonstrate that non-smokers may also develop chronic airflow limitation [3]. Compared to smokers with COPD, never smokers with chronic airflow limitation have fewer symptoms, milder disease and a lower burden of systemic inflammation [4]. Never smokers with chronic airflow limitation do not have an increased risk of lung cancer, or cardiovascular comorbidities; however, they have an increased risk of pneumonia and mortality from respiratory failure [4].

Processes occurring during gestation, birth, and exposures during childhood and adolescence affect lung growth $[5,6]$. Reduced maximal attained lung function (as measured by spirometry) may identify individuals at increased risk for COPD [2, 7]. Factors in early life termed "childhood disadvantage factors" are as important as heavy smoking in predicting lung function in adult life [8]. An examination of three different longitudinal cohorts found that approximately 50\% of patients developed COPD owing to an accelerated decline in forced expiratory volume in $1 \mathrm{~s}(\mathrm{FEV} 1)$; the other $50 \%$ developed COPD owing to abnormal lung growth and development.

This document is an executive summary of the Global Strategy for the Diagnosis, Management, and Prevention of COPD (GOLD) 2017 Report. The documents were peer reviewed by GOLD before submission to the European Respiratory Journal, the American Journal of Respiratory and Critical Care Medicine, Archivos de Bronconeumología and Respirology for joint publication. 
Cigarette smokers have a higher prevalence of respiratory symptoms and lung function abnormalities, a greater annual rate of decline in FEV1, and a greater COPD mortality rate than non-smokers [9]. Other types of tobacco (e.g., pipe, cigar, water pipe) [10-12] and marijuana [13] are also risk factors for COPD. Passive exposure to cigarette smoke, also known as environmental tobacco smoke (ETS), may also contribute to respiratory symptoms and COPD [14] by increasing the lung's total burden of inhaled particles and gases. Smoking during pregnancy may pose a risk for the fetus by affecting in utero lung growth and development, and possibly priming the immune system [15].

Occupational exposures, including organic and inorganic dusts, chemical agents and fumes, are under-appreciated risk factors for COPD development $[16,17]$.

Wood, animal dung, crop residues, and coal, typically burned in open fires or poorly functioning stoves, may lead to indoor air pollution [18]. Indoor pollution from biomass cooking and heating, in poorly ventilated dwellings, is a risk for COPD [19-21].

Asthma may be a risk for the development of chronic airflow limitation and COPD [22].

Airway hyper-responsiveness can exist without a clinical diagnosis of asthma and is an independent predictor of COPD and respiratory mortality in population studies [23, 24], and may indicate a risk for excessive lung function decline in mild COPD [25].

A history of severe childhood respiratory infection is associated with reduced lung function and increased respiratory symptoms in adulthood [26]. HIV infection accelerates the onset of smoking-related emphysema and COPD [27]; tuberculosis has also been identified as a risk for COPD as well as a potential comorbidity [28-30].

\section{Diagnosis and initial assessment}

\section{Key points}

- COPD should be considered in any patient with dyspnoea, chronic cough or sputum production, and/or a history of exposure to risk factors.

- Spirometry is required to make the diagnosis; a post-bronchodilator FEV $1 /$ forced vital capacity (FVC) $<0.70$ confirms the presence of persistent airflow limitation.

- The goals of COPD assessment are to determine the level of airflow limitation, the impact of disease on the patient's health status, and the risk of future events (such as exacerbations, hospital admissions, or death) to guide therapy.

- Concomitant chronic diseases occur frequently in COPD patients and should be treated because they can independently affect mortality and hospitalisations.

\section{Diagnosis}

COPD should be considered in any patient with dyspnoea, chronic cough or sputum production, and/or a history of exposure to risk factors for the disease (figure 1 and table 1). Spirometry is required to make the diagnosis in this clinical context [31]; a post-bronchodilator $\mathrm{FEV} 1 / \mathrm{FVC}<0.70$ confirms the presence of persistent airflow limitation and identifies the presence of COPD in patients with appropriate symptoms and predisposing risks.

\section{Symptoms}

Chronic and progressive dyspnoea is the most characteristic symptom of COPD.

\section{Dyspnoea}

Dyspnoea is a major cause of disability and anxiety in COPD [32]. The terms used to describe dyspnoea vary individually and culturally [33].

FIGURE 1 Pathways to the diagnosis of chronic obstructive pulmonary disease.

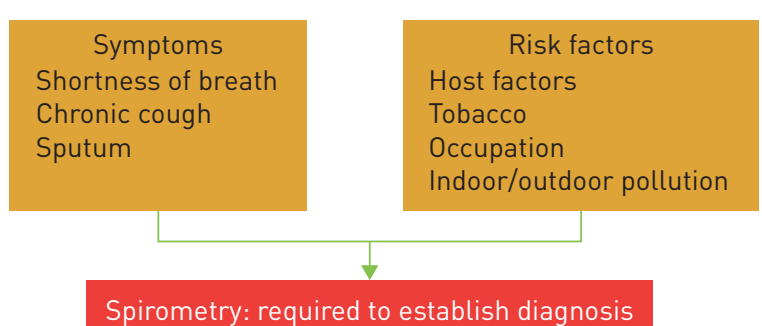

Spirometry: required to establish diagnosis 
TABLE 1 Key indicators for considering a diagnosis of chronic obstructive pulmonary disease (COPD)

Consider COPD, and perform spirometry, if any of these indicators are present in an individual over age 40. These indicators are not diagnostic themselves, but the presence of multiple key indicators increases the probability of a diagnosis of COPD. Spirometry is required to establish a diagnosis of COPD.

Dyspnoea that is

Chronic cough

Chronic sputum production

Recurrent lower respiratory tract infections History of risk factors

\author{
Progressive over time \\ Characteristically worse with exercise \\ Persistent \\ May be intermittent and may be unproductive \\ Recurrent wheeze \\ With any pattern \\ Host factors (such as genetic factors, congenital/developmental abnormalities etc.) \\ Tobacco smoke \\ Smoke from home cooking and heating fuels \\ Occupational dusts, vapours, fumes, gases and other chemicals \\ For example low birthweight, childhood respiratory infections
}

Family history of COPD and/or childhood factors

Cough

Chronic cough is often the first symptom of COPD and frequently discounted by the patient as a consequence of smoking and/or environmental exposures.

Sputum production

Regular sputum production $\geqslant 3$ months in 2 consecutive years is the classical definition of chronic bronchitis [34]; an arbitrary definition that does not reflect the range of sputum production reported in COPD. Patients producing large volumes of sputum may have underlying bronchiectasis.

Wheezing and chest tightness

Wheezing and chest tightness may vary between days, and throughout a single day.

Additional features in severe disease

Fatigue, weight loss and anorexia are common in patients with more severe forms of COPD [35, 36].

Medical history

A detailed medical history of any patient who is known, or suspected, to have COPD should include:

- Exposure to risk factors, such as smoking and occupational or environmental exposures.

- Past medical history, including asthma, allergy, sinusitis, or nasal polyps; respiratory infections in childhood; other chronic respiratory and non-respiratory diseases.

- Family history of COPD or other chronic respiratory diseases.

- Pattern of symptom development: age of onset, type of symptom, more frequent or prolonged "winter colds," and social restriction.

- History of exacerbations or previous hospitalisations for a respiratory disorder.

- Presence of comorbidities, such as heart disease, osteoporosis, musculoskeletal disorders, and malignancies.

- Impact of disease on patient's life, including limitation of activity, missed work and economic impact, and feelings of depression or anxiety.

- Social and family support available to the patient.

- Possibilities for reducing risk factors, especially smoking cessation.

\section{Physical examination}

Although important for general health, a physical examination is rarely diagnostic in COPD. Physical signs of airflow limitation/hyperinflation are usually not identifiable until significantly impaired lung function is present $[37,38]$.

\section{Spirometry}

Spirometry is the most reproducible and objective measurement of airflow limitation. It is a noninvasive and readily available test. Good quality spirometry is possible in any healthcare setting; all healthcare workers who care for COPD patients should have access to spirometry. 
A post-bronchodilator fixed ratio of $\mathrm{FEV} 1 / \mathrm{FVC}<0.70$ is the spirometric criterion for airflow limitation. This criterion is simple and independent of reference values and has been used in numerous clinical trials. However, it may result in more frequent diagnosis of COPD in the elderly [39, 40], and less frequent diagnosis in adults $<45$ years [40], especially in mild disease, compared to a cut-off based on the lower limit of normal (LLN) values for FEV1/FVC. Several limitations occur with using LLN as the diagnostic criterion for spirometric obstruction: 1) LLN values are dependent on the choice of reference equations that use post-bronchodilator FEV1, 2) there are no longitudinal studies that validate using the LLN, and 3) studies using LLN in populations where smoking is not the major cause of COPD are lacking.

Normal spirometry may be defined by a new approach from the Global Lung Initiative (GLI) [41, 42]. Using GLI equations, $z$ scores were calculated for FEV1, FVC, and FEV1/FVC and compared to fixed ratio data. The findings suggest that among adults with GLI-defined normal spirometry, the use of a fixed ratio may misclassify individuals as having respiratory impairment. These findings await additional study in other cohorts.

The risk of misdiagnosis and over-treatment using the fixed ratio as a diagnostic criterion is limited since spirometry is only one parameter used to establish the clinical diagnosis of COPD. GOLD favours using the fixed ratio over LLN since diagnostic simplicity and consistency are crucial for the busy clinician.

Assessing the degree of reversibility of airflow limitation (e.g., measuring FEV1 before and after bronchodilator or corticosteroids) to make therapeutic decisions is not recommended [43] since it does not aid the diagnosis of COPD, differentiate COPD from asthma, or predict the long-term response to treatment [44].

In asymptomatic individuals without exposures to tobacco or other noxious stimuli, screening spirometry is not indicated. However, in those with symptoms and/or risk factors (e.g. $>20$ pack-years of smoking or recurrent chest infections), the diagnostic yield for COPD is relatively high and spirometry should be considered [45, 46]. GOLD advocates active case finding $[45,47]$ i.e., performing spirometry in patients with symptoms and/or risk factors, but not routine screening spirometry in asymptomatic individuals without COPD risk factors.

\title{
Assessment
}

The goals of COPD assessment to guide therapy are 1) to determine the level of airflow limitation; 2) to define its impact on the patient's health status and; 3) to identify the risk of future events (such as exacerbations, hospital admissions or death).

To achieve these goals, COPD assessment must consider separately the following aspects of the disease:

- Presence and severity of the spirometric abnormality

- Current nature and magnitude of symptoms

- History/future risk of exacerbations

- Presence of comorbidities

\section{Classification of severity of airflow limitation}

Spirometry should be performed after administration of an adequate dose of at least one short-acting inhaled bronchodilator in order to minimise variability.

The role of spirometry for the diagnosis, assessment and follow-up of COPD is summarised in table 2.

\section{Assessment of symptoms}

COPD was previously viewed as a disease largely characterised by breathlessness. A simple measure of breathlessness such as the Modified British Medical Research Council (mMRC) Questionnaire [48] was considered adequate for assessment of symptoms [49-51]. However, COPD impacts patients well beyond dyspnoea [52]. For this reason, a comprehensive assessment of symptoms is recommended. The most

\section{TABLE 2 Role of spirometry}

\author{
Diagnosis \\ Assessment of severity of airflow obstruction (for prognosis) \\ Follow-up assessment \\ Therapeutic decisions \\ Pharmacological in selected circumstances (e.g., discrepancy between spirometry and level of \\ symptoms) \\ Consider alternative diagnoses when symptoms are disproportionate to degree of airflow obstruction \\ Nonpharmacological (e.g., interventional procedures) \\ Identification of rapid decline
}


comprehensive disease-specific health status questionnaires include the Chronic Respiratory Questionnaire (CRQ) [53] and St. George's Respiratory Questionnaire (SGRQ) [54]. These are too complex to use in clinical practice, but shorter measures e.g., the COPD Assessment Test (CAT) are suitable.

Choice of thresholds

SGRQ scores $<25$ are uncommon in COPD patients [55] and scores $\geqslant 25$ are very uncommon in healthy persons [56, 57]. The equivalent cut-off point for the CAT is 10 [58]. A mMRC threshold of $\geqslant 2$ is used to separate "less breathlessness" from "more breathlessness".

Assessment of exacerbation risk

The best predictor of frequent exacerbations (defined as $\geqslant 2$ exacerbations per year) is a history of earlier treated events [59]. Hospitalisation for a COPD exacerbation has a poor prognosis and an increased risk of death [60].

\section{Blood eosinophil count}

Post-hoc analysis of two clinical trials in COPD patients with an exacerbation history showed that higher blood eosinophil counts may predict increased exacerbation rates in patients treated with long acting beta agonists (LABA) (without inhaled corticosteroid, ICS) [61, 62]. The treatment effect of ICS/LABA versus LABA on exacerbations was greater in patients with higher blood eosinophil counts. These findings suggest that blood eosinophil counts are 1) a biomarker of exacerbation risk in patients with a history of exacerbations and 2) can predict the effects of ICS on exacerbation prevention. Prospective trials are required to validate the use of blood eosinophil counts to predict ICS effects, to determine a cut-off threshold for blood eosinophils that predicts exacerbation risk, and to clarify blood eosinophil cut-off values that could be used in clinical practice.

\section{Assessment of concomitant chronic diseases (comorbidities)}

Patients with COPD often have important concomitant chronic illnesses as COPD represents an important component of multimorbidity particularly in the elderly [60, 63-65].

\section{Revised combined COPD assessment}

The "ABCD" assessment tool of the 2011 GOLD Report was a major step forward from the simple spirometric grading system of earlier GOLD Reports because it incorporated patient-reported outcomes and highlighted the importance of exacerbation prevention in COPD management. However, there were important limitations. ABCD assessment performed no better than spirometric grades for mortality prediction or other important health outcomes [66-68]. Moreover, group " $D$ " outcomes were modified by two parameters: lung function and/or exacerbation history, which caused confusion [69]. To address these concerns, the 2017 GOLD Report provides a refinement of the ABCD assessment that separates spirometric grades from ABCD groupings. For some therapy recommendations, especially pharmacologic treatments, $\mathrm{ABCD}$ groups are derived exclusively from patient symptoms and their exacerbation history. However, spirometry, in conjunction with patient symptoms and exacerbation history, remains vital for the diagnosis, prognostication and consideration of other important therapeutic approaches, especially nonpharmacological therapies. This new approach to assessment is illustrated in figure 2.

In the refined assessment scheme, patients should undergo spirometry to determine the severity of airflow limitation (i.e., spirometric grade). They should also undergo assessment of either dyspnoea using mMRC or symptoms using CAT. Finally, their history of exacerbations (including prior hospitalisations) should be recorded.

The number provides information regarding severity of airflow limitation (spirometric grades 1-4) while the letter (groups A-D) provides information regarding symptom burden and risk of exacerbation. FEV1 is a very important parameter at the population level in the prediction of important clinical outcomes such as mortality and hospitalisations or prompting consideration for nonpharmacologic therapies such as lung reduction or lung transplantation. However, at the individual patient level, FEV1 loses precision and thus cannot be used alone to determine all therapeutic options. Furthermore, in some circumstances, such as during hospitalisation or urgent presentation to the clinic or emergency room, the ability to assess patients based on symptoms and exacerbation history, independent of the spirometric value, allows clinicians to initiate a treatment plan based on the revised ABCD scheme. This approach acknowledges the limitations of FEV1 in making treatment decisions for individualised patient care and highlights the importance of patient symptoms and exacerbation risks in guiding therapies in COPD. The separation of airflow limitation from clinical parameters makes it clearer what is being evaluated and ranked. This should facilitate more precise treatment recommendations based on parameters that are driving the patient's symptoms at any given time. 


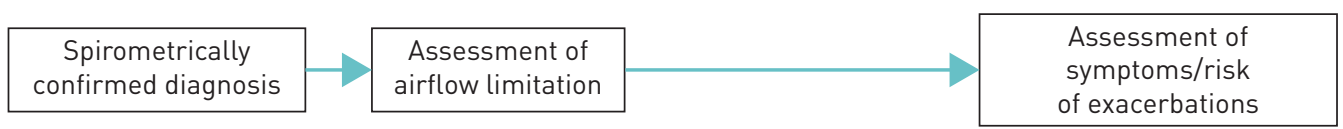

Post-bronchodilator FEV $1 / F V C<0.7$

\begin{tabular}{|c|c|}
\hline \multicolumn{2}{|c|}{$\begin{array}{c}\text { FEV } 1 \\
\% \text { predicted }\end{array}$} \\
\hline GOLD 1 & $\geqslant 80$ \\
\hline GOLD 2 & $50-79$ \\
\hline GOLD 3 & $30-49$ \\
\hline GOLD 4 & $<30$ \\
\hline
\end{tabular}

symptoms/risk

of exacerbations

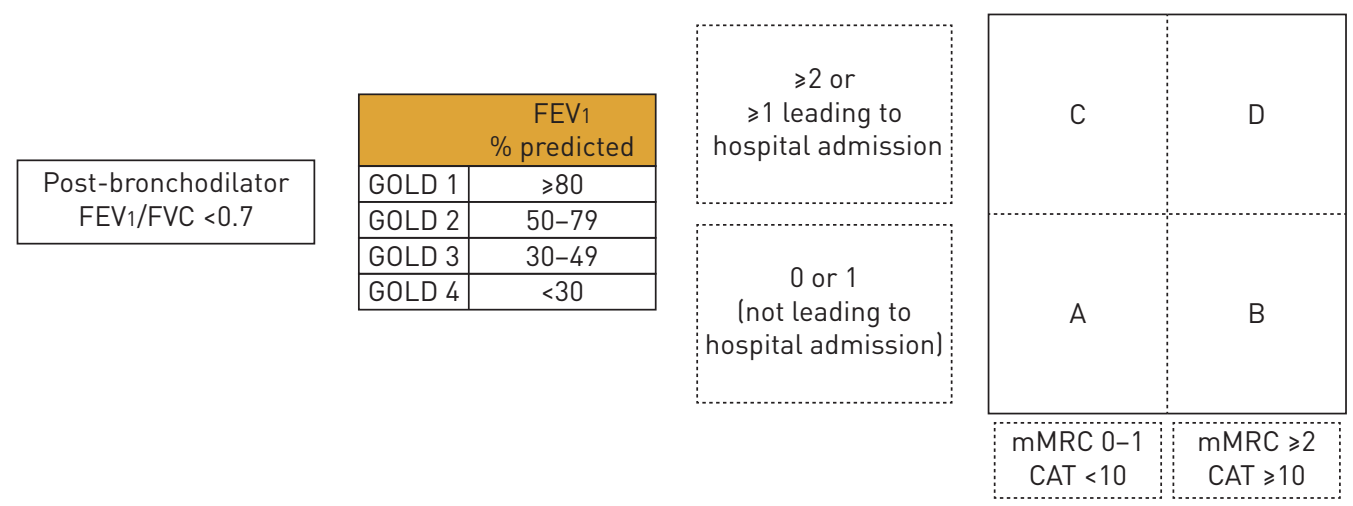

FIGURE 2 The refined ABCD assessment tool. FEV1: forced expiratory volume in $1 \mathrm{~s}$; FVC: forced vital capacity; GOLD: Global Initiative for Chronic Obstructive Lung Disease; mMRC: modified Medical Research Council; CAT: COPD Assessment Test.

\section{Example}

Consider two patients - both patients with FEV $1<30 \%$ of predicted and CAT scores of 18 , and one with no exacerbations in the past year, and the other with three exacerbations in the past year. Both would have been labelled GOLD D in the prior classification scheme. However, with the new proposed scheme, the subject with 3 exacerbations in the past year would be labelled GOLD grade 4, group D. Individual decisions on pharmacotherapeutic approaches would use the recommendations based on the $\mathrm{ABCD}$ assessment to treat the patient's major problem at this time, i.e., persistent exacerbations. The other patient, who has had no exacerbations, would be classified as GOLD grade 4, group B. In such patients besides pharmacotherapy and rehabilitation - lung reduction, lung transplantation or bullectomy may be important therapeutic considerations given their symptom burden and level of spirometric limitation.

\section{$\alpha_{1}$-antitrypsin deficiency}

The World Health Organization recommends that all patients with a diagnosis of COPD be screened once for $\alpha_{1}$-antitrypsin deficiency [70]. A low concentration $(<20 \%$ normal $)$ is suggestive of homozygous deficiency. Family members should be screened and together with the patient referred to specialist centres for advice and management.

\section{Additional investigations}

In order to rule out other concomitant disease contributing to respiratory symptoms, or in cases where patients do not respond to the treatment plan as expected, additional testing may be required. Thoracic imaging (chest X-ray, chest computed tomography (CT)), assessment of lung volumes and/or diffusion capacity, oximetry and arterial blood gas measurement, and exercise testing and assessment of physical activity should be considered.

Composite scores

The BODE (body mass index, obstruction, dyspnoea, and exercise) method gives a composite score that is a better predictor of subsequent survival than any single component [71]. Simpler alternatives that do not include exercise testing need validation to confirm suitability for routine clinical use $[72,73]$.

\section{Differential diagnoses}

In some patients, features of asthma and COPD may coexist. The terms "asthma-COPD overlap syndrome" or "asthma-COPD overlap" acknowledge the overlap of these two common disorders causing chronic airflow limitation rather than designating it a distinct syndrome. Most other potential differential diagnoses are easier to distinguish from COPD.

\section{Other considerations}

Some patients without evidence of airflow limitation have evidence of structural lung disease on chest imaging (emphysema, gas trapping, airway wall thickening). Such patients may report exacerbations of 
respiratory symptoms or even require treatment with respiratory medications on a chronic basis. Whether these patients have acute or chronic bronchitis, a persistent form of asthma or an earlier presentation of what will become COPD as it is currently defined, is unclear and requires further study.

\section{Prevention and maintenance therapy}

\section{Key points}

- Smoking cessation is key. Pharmacotherapy and nicotine replacement increase long-term smoking abstinence rates.

- The effectiveness and safety of e-cigarettes as a smoking cessation aid is uncertain.

- Pharmacologic therapy can reduce COPD symptoms, reduce the frequency and severity of exacerbations, and improve health status and exercise tolerance.

- Each pharmacologic treatment regimen should be individualised and guided by the severity of symptoms, risk of exacerbations, side-effects, comorbidities, drug availability and cost, and the patient's response, preference and ability to use various drug delivery devices.

- Inhaler technique needs to be assessed regularly.

- Influenza and pneumococcal vaccinations decrease the incidence of lower respiratory tract infections.

- Pulmonary rehabilitation improves symptoms, quality of life, and physical and emotional participation in everyday activities.

- In patients with severe resting chronic hypoxaemia, long-term oxygen therapy improves survival.

- In patients with stable COPD and resting or exercise-induced moderate desaturation, long-term oxygen treatment should not be prescribed routinely, however, individual patient factors should be considered.

- In patients with severe chronic hypercapnia and a history of hospitalisation for acute respiratory failure, long-term non-invasive ventilation (NIV) may decrease mortality and prevent re-hospitalisation.

- In select patients with advanced emphysema refractory to optimised medical care, surgical or bronchoscopic interventional treatments may be beneficial.

- Palliative approaches are effective in controlling symptoms in advanced COPD.

\section{Smoking cessation}

Smoking cessation influences the natural history of COPD. If effective resources and time are dedicated to smoking cessation, long-term quit success rates of up to $25 \%$ can be achieved [74].

\section{Nicotine replacement products}

Nicotine replacement therapy increases long-term smoking abstinence rates [75-77] and is more effective than placebo. E-cigarettes are increasingly used as a form of nicotine replacement therapy, although their efficacy remains controversial [78-82].

\section{Pharmacologic products}

Varenicline [83], bupropion [84], and nortriptyline [85] increase long-term quit rates [85], but should be used as part of an interventional programme rather than as a sole intervention.

\section{Smoking cessation programmes}

A five-step programme for intervention [75] provides a framework to guide healthcare providers to help patients stop smoking $[75,77,86]$. Counselling delivered by health professionals significantly increases quit rates over self-initiated strategies [87]. The combination of pharmacotherapy and behavioural support increases smoking cessation rates [88].

\section{Vaccinations}

Influenza vaccine and pneumococcal vaccines

Influenza vaccination reduces serious illness [89], death [90-93], the risk of ischaemic heart disease [94] and the total number of exacerbations [90]. Vaccines containing either killed or live inactivated viruses are recommended [95] as they are more effective in elderly patients with COPD [96].

The pneumococcal vaccinations, the 13-valent pneumococcal conjugate vaccine (PCV13) and 23-valent pneumococcal polysaccharide vaccine (PPSV23), are recommended for all patients $\geqslant 65$ years of age (table S2).

Pharmacologic therapy for stable COPD

Overview of medications

Pharmacologic therapy for COPD reduces symptoms, the frequency and severity of exacerbations, and improves exercise tolerance and health status. No existing medication modifies the long-term decline in 
lung function [97-101]. The classes of medications used to treat COPD are shown in table S3. The choice within each class depends on the availability and cost of medication and favourable clinical response balanced against side-effects. Each treatment regimen needs to be individualised as the relationship between severity of symptoms, airflow limitation, and severity of exacerbations varies between patients.

\section{Bronchodilators}

Bronchodilators increase FEV1, reduce dynamic hyperinflation, at rest and during exercise [102, 103], and improve exercise performance. Bronchodilator medications are usually given on a regular basis to prevent or reduce symptoms. Toxicity is dose-related.

$\beta_{2}$-agonists

$\beta_{2}$-agonists, including short-acting (SABA) and long-acting (LABA) agents, relax airway smooth muscle. Stimulation of $\beta_{2}$-adrenergic receptors can produce resting sinus tachycardia and precipitate cardiac rhythm disturbances in susceptible patients. Exaggerated somatic tremor occurs in some patients treated with higher doses of $\beta_{2}$-agonists.

Antimuscarinic drugs

Ipratropium, a short-acting muscarinic antagonist, provides small benefits over short-acting $\beta_{2}$-agonist in terms of lung function, health status and requirement for oral steroids [104]. Long-acting muscarinic antagonist (LAMA) treatment improves symptoms and health status [105, 106], improves the effectiveness of pulmonary rehabilitation [107, 108] and reduces exacerbations and related hospitalisations[107]. Clinical trials have shown a greater effect on exacerbation rates for LAMA treatment (tiotropium) versus LABA treatment $[109,110]$. An unexpected small increase in cardiovascular events was reported in COPD patients regularly treated with ipratropium bromide $[111,112]$. A large trial reported no difference in mortality, cardiovascular morbidity or exacerbation rates when using tiotropium as a dry-powder inhaler compared to a mist delivered by the Respimat inhaler [113].

\section{Methylxanthines}

Theophylline exerts a modest bronchodilator effect in stable COPD [114], and improves FEV1 and breathlessness when added to salmeterol $[115,116]$. There is limited and contradictory evidence regarding the effect of low-dose theophylline on exacerbation rates [114, 119]. Toxicity is dose-related, which is a problem as most of the benefit occurs when near-toxic doses are given $[116,121]$.

\section{Combination bronchodilator therapy}

Combining bronchodilators with different mechanisms and durations of action may increase the degree of bronchodilation with a lower risk of side-effects compared to increasing the dose of a single bronchodilator (table 3) [120]. There are numerous combinations of a LABA and LAMA in a single inhaler available (table S3). These combinations improve lung function compared to placebo [120] and

\section{TABLE 3 Bronchodilators in stable chronic obstructive pulmonary disease (COPD)}

Inhaled bronchodilators in COPD are central to symptom management and commonly given on a regular basis to prevent or reduce symptoms (evidence A)

Regular and as-needed use of SABA or SAMA improves FEV1 and symptoms (evidence A)

Combinations of SABA and SAMA are superior compared to either medication alone in improving FEV 1 and symptoms (evidence A)

LABAs and LAMAs significantly improve lung function, dyspnoea, health status, and reduce exacerbation rates (evidence $A$ )

LAMAs have a greater effect on exacerbation reduction compared with LABAs (evidence A) and decrease hospitalisations (evidence B)

Combination treatment with a LABA and LAMA increases FEV1 and reduces symptoms compared to monotherapy (evidence A)

Combination treatment with a LABA and LAMA reduces exacerbations compared to monotherapy (evidence B) or ICS/LABA (evidence B)

Tiotropium improves the effectiveness of pulmonary rehabilitation in increasing exercise performance (evidence B)

Theophylline exerts a small bronchodilator effect in stable COPD (evidence A) that is associated with modest symptomatic benefits (evidence B)

SABA: short-acting $\beta_{2}$-agonist; SAMA: short-acting muscarinic antagonist; FEV1: forced expiratory volume in $1 \mathrm{~s}$; LABA: long-acting $\beta_{2}$-agonist; ICS: inhaled corticosteroid. 
have a greater impact on patient reported outcomes compared to monotherapies [121-124]. LABA/LAMA improves symptoms and health status in COPD patients [125], is more effective than long-acting bronchodilator monotherapy for preventing exacerbations [126], and decreases exacerbations to a greater extent than ICS/LABA combination [127].

\section{Anti-inflammatory agents}

Exacerbations represent the main clinically relevant end-point used for the efficacy assessment of anti-inflammatory drugs (table 4 ).

\section{Inhaled corticosteroids}

In patients with moderate to very severe COPD and exacerbations, an ICS combined with a LABA is more effective than either component alone in improving lung function and health status, and reducing exacerbations $[128,129]$. However, survival is not affected by combination therapy $[130,131]$.

ICS use has a higher prevalence of oral candidiasis, hoarse voice, skin bruising and pneumonia [132]. Patients at higher risk of pneumonia include those who currently smoke, are aged $\geqslant 55$ years, or have a history of prior exacerbations or pneumonia, a body mass index (BMI) $<25 \mathrm{~kg} \cdot \mathrm{m}^{-2}$, a poor MRC dyspnoea grade and/or severe airflow limitation [133].

Results from randomised controlled trials (RCTs) have yielded variable results regarding the risk of decreased bone density and fractures with ICS treatment [99, 134-137]. Observational studies suggest that ICS treatment could be associated with increased risks of diabetes/poor control of diabetes [138], cataracts [139], and mycobacterial infection [140] including tuberculosis [141, 142].

\section{ICS withdrawal}

Withdrawal studies provide equivocal results regarding the consequences of withdrawal on lung function, symptoms and exacerbations [143-147].

\section{TABLE 4 Anti-inflammatory therapy in stable chronic obstructive pulmonary disease (COPD)}

ICS

An ICS combined with a LABA is more effective than the individual components in improving lung function and health status and reducing exacerbations in patients with exacerbations and moderate to very severe COPD (evidence A)

Regular treatment with ICS increases the risk of pneumonia especially in those with severe disease (evidence A)

Triple inhaled therapy of ICS/LAMA/LABA improves lung function, symptoms and health status (evidence A) and reduces exacerbations (evidence B) compared to ICS/LABA or LAMA monotherapy

Oral glucocorticoids

Long-term use of oral glucocorticoids has numerous side-effects (evidence A) with no evidence of benefits (evidence $\mathrm{C}$ )

\section{PDE4 inhibitors}

In patients with chronic bronchitis, severe to very severe COPD and a history of exacerbations A PDE4 inhibitor improves lung function and reduces moderate and severe exacerbations (evidence A) A PDE4 inhibitor improves lung function and decreases exacerbations in patients who are on fixed-dose LABA/ICS combinations (evidence B)

\section{Antibiotics}

Long-term azithromycin and erythromycin therapy reduces exacerbations over 1 year (evidence A)

Treatment with azithromycin is associated with an increased incidence of bacterial resistance (evidence A) and hearing test impairment (evidence B)

\section{Mucolytics/antioxidants}

Regular use of NAC and carbocysteine reduces the risk of exacerbations in select populations (evidence B)

\section{Other anti-inflammatory agents}

Simvastatin does not prevent exacerbations in COPD patients at increased risk of exacerbations and without indications for statin therapy (evidence A); however, observational studies suggest that statins may have positive effects on some outcomes in patients with COPD who receive them for cardiovascular and metabolic indications (evidence $\mathrm{C}$ )

Leukotriene modifiers have not been tested adequately in COPD patients

ICS: inhaled corticosteroid; LABA: long-acting $\beta_{2}$-agonist; LAMA: long-acting muscarinic antagonist; PDE: phosphodiesterase; $N$-acetylcysteine. 


\section{Triple inhaled therapy}

Combination of LABA plus LAMA plus ICS (triple therapy) may improve lung function and patient reported outcomes [148-151] and reduce exacerbation risk [149, 152-154]. However, one RCT failed to demonstrate any benefit of adding an ICS to LABA plus LAMA on exacerbations [155]. More evidence is needed to compare the benefits of triple therapy (LABA/LAMA/ICS) to LABA/LAMA.

\section{Oral glucocorticoids}

Oral glucocorticoids have no role in the chronic daily treatment of COPD because of a lack of benefit balanced against a high rate of systemic complications.

\section{Phosphodiesterase-4 inhibitors}

Roflumilast reduces moderate and severe exacerbations treated with systemic corticosteroids in patients with chronic bronchitis, severe to very severe COPD, and a history of exacerbations [156]. Phosphodiesterase-4 (PDE4) inhibitors have more adverse effects than inhaled medications for COPD [157]. The most frequent are diarrhoea, nausea, reduced appetite, weight loss, abdominal pain, sleep disturbance, and headache. Roflumilast should be avoided in underweight patients and used with caution in patients with depression.

\section{Antibiotics}

Azithromycin (250 mg.day ${ }^{-1}$ or $500 \mathrm{mg}$ three times per week) or erythromycin (500 $\mathrm{mg}$ two times per day) for 1 year reduces the risk of exacerbations in patients prone to exacerbations [158-160]. Azithromycin use showed a reduced exacerbation rate in former smokers only and was associated with an increased incidence of bacterial resistance and impaired hearing tests [160]. Pulse moxifloxacin therapy in patients with chronic bronchitis and frequent exacerbations does not reduce exacerbation rate [161].

Mucolytic (mucokinetics, mucoregulators) and antioxidant agents ( $\mathrm{N}$-acetylcysteine, carbocysteine) Regular treatment with mucolytics such as carbocysteine and $N$-acetylcysteine may reduce exacerbations and modestly improve health status in patients not receiving ICS [162, 163].

Other drugs with anti-inflammatory potential

Although RCTs suggest that immunoregulators decrease the severity and frequency of exacerbations [164, 165], the long-term effects of this therapy are unknown. Nedocromil and leukotriene modifiers have not been adequately tested in COPD [166]. There was no evidence of benefit, and some evidence of harm, following treatment with an anti-tumour necrosis factor- $\alpha$ antibody (infliximab) in moderate to severe COPD [167]. Simvastatin did not prevent exacerbations in patients with COPD who had no metabolic or cardiovascular indication for statin treatment [168]. An association between statin use and improved outcomes has been reported in observational studies of patients with COPD who received them for cardiovascular and metabolic indications [169]. There is no evidence that vitamin D supplementation reduces exacerbations in unselected patients [170].

\section{Issues related to inhaled delivery}

Observational studies have identified a significant relationship between poor inhaler use and symptom control in COPD [171]. Determinants of poor inhaler technique include older age, use of multiple devices, and lack of previous education on inhaler technique [172]. Education improves inhalation technique in some but not all patients [172], especially when the "teach-back" approach is implemented [173].

Other pharmacologic treatments for COPD are summarised in table S4.

$\alpha_{1}$-Antitrypsin augmentation therapy

Observational studies suggest a reduction in spirometric progression in $\alpha_{1}$-antitrypsin deficiency patients treated with augmentation therapy versus non-treated patients [174]. Studies using sensitive parameters of emphysema progression determined by CT scans provide evidence for an effect on preserving lung tissue compared to placebo [175-177].

\section{Antitussives}

The role of antitussives in patients with COPD is inconclusive [178].

\section{Vasodilators}

Available studies report worsening gas exchange [179] with little improvement in exercise capacity or health status in COPD patients $[180,181]$. 
Rehabilitation, education, and self-management

Pulmonary rehabilitation

Pulmonary rehabilitation is a comprehensive intervention based on thorough patient assessment followed by patient-tailored therapies (e.g., exercise training, education, self-management interventions aimed at behaviour changes to improve physical and psychological condition and promote adherence to health-enhancing behaviours in patients with COPD) [182]. The benefits of pulmonary rehabilitation are considerable (table S5). Pulmonary rehabilitation can reduce readmissions and mortality in patients following a recent exacerbation ( $\leqslant 4$ weeks from prior hospitalisation) [183]. Initiating pulmonary rehabilitation before hospital discharge, however, may compromise survival [184].

Pulmonary rehabilitation represents integrated patient management that includes a range of healthcare professionals [185] and sites, including hospital inpatient and outpatient settings and/or the patient's home [182].

\section{Education, self-management, and integrative care}

\section{Education}

Smoking cessation, correct use of inhaler devices, early recognition of exacerbation, decision making, when to seek help, surgical interventions, and the consideration of advance directives, are examples of educational topics.

\section{Self-management}

Self-management interventions that use written negotiated action plans for worsening symptoms may lead to less respiratory-related hospitalisation and all cause hospitalisations and improved health status [186]. The health benefits of COPD self-management programmes may be negated by increased mortality [187, 188]. Generalisation to real life remains difficult.

\section{Integrated care programmes}

Integrated care programmes improve several clinical outcomes, although not mortality [189]. However, a large multi-centre study within an existing well-organised system of care did not confirm this [190]. Delivering integrated interventions by telemedicine provided no significant benefit [191].

Supportive, palliative, end-of-life, and hospice care

Symptom control and palliative care

The goal of palliative care is to prevent and relieve suffering, and to improve quality of life for patients and their families, regardless of the stage of disease or the need for other therapies [192]. Palliation efforts should be focussed on the relief of dyspnoea, pain, anxiety, depression, fatigue, and poor nutrition.

\section{End-of-life and hospice care}

End-of-life care discussions should include patients and their families [193]. Advance care planning can reduce anxiety for patients and their families; ensure that care is consistent with their wishes and avoid unnecessary, unwanted and costly invasive therapies [194, 195] (table S6) the approach to palliation, end-of-life and hospice care

\section{Other treatments}

Oxygen therapy and ventilatory support

Oxygen therapy

The long-term administration of oxygen ( $>15 \mathrm{~h}$ per day) to patients with chronic respiratory failure increases survival in patients with severe resting hypoxaemia [196]. Long-term oxygen therapy does not lengthen time to death or first hospitalisation or provide sustained benefit for any of the measured outcomes in patients with stable COPD and resting or exercise-induced moderate arterial oxygen desaturation [197].

\section{Ventilatory support}

Whether to use noninvasive positive pressure ventilation (NPPV) chronically at home to treat patients with acute on chronic respiratory failure following hospitalisation remains undetermined. Retrospective studies have provided inconclusive data $[198,199]$. RCTs have yielded conflicting data on the use of home NPPV on survival and re-hospitalisation in chronic hypercapnic COPD [200-203]. In patients with both COPD and obstructive sleep apnoea (OSA) continuous positive airway pressure improves survival and avoids hospitalisation (table S7) [204]. 


\section{Interventional therapy}

Surgical interventions

Lung volume reduction surgery

A RCT confirmed that COPD patients with upper-lobe emphysema and low post-rehabilitation exercise capacity experienced improved survival when treated with lung volume reduction surgery (LVRS) compared to medical treatment [205]. In patients with high post-pulmonary rehabilitation exercise capacity, no difference in survival was noted after LVRS, although health status and exercise capacity improved. LVRS has been demonstrated to result in higher mortality than medical management in severe emphysema patients with an $\mathrm{FEV}_{1} \leqslant 20 \%$ predicted and either homogeneous emphysema in high-resolution computed tomography (HRCT) or a diffusing capacity of the lung for carbon monoxide of $\leqslant 20 \%$ of predicted [206].

\section{Bullectomy}

In selected patients with relatively preserved underlying lung, bullectomy is associated with decreased dyspnoea, improved lung function and exercise tolerance [207].

\section{Lung transplantation}

In selected patients lung transplantation has been shown to improve health status and functional capacity but not to prolong survival [207-209]. Bilateral lung transplantation has been reported to have longer survival than single lung transplantation in COPD patients, especially those $<60$ years of age [210].

\section{Bronchoscopic interventions to reduce hyperinflation in severe emphysema}

Less invasive bronchoscopic approaches to lung reduction have been developed [211]. Prospective studies have shown that the use of bronchial stents is not effective [212] while use of lung sealant caused significant morbidity and mortality [213]. A RCT of endobronchial valve placement showed statistically significant improvements in FEV1 and 6-min walk distance compared to control therapy at 6 months post intervention [214] but the magnitude of the observed improvements was not clinically meaningful. Subsequently, efficacy of the same endobronchial valve has been studied in patients with heterogeneous [215], or heterogeneous and homogenous emphysema [216] with mixed outcomes.

Two multi-centre trials have examined nitinol coils implanted into the lung compared to usual care reported increases in 6-min walk distance with coil treatment compared to control and smaller improvements in FEV1 and quality of life measured by St George's Respiratory Questionnaire [217, 218].

Additional data are needed to define the optimal patient population to receive a specific bronchoscopic lung volume technique and to compare the long-term durability of improvements in functional or physiological performance to LVRS relative to side effects [218].

Key points for interventional therapy in stable COPD are summarised in table S8.

\section{Management of stable COPD}

\section{Key points}

- The management strategy for stable COPD should be based on individualised symptom assessment and future risk of exacerbations.

- All individuals who smoke should be supported to quit.

- The main treatment goals are reduction of symptoms and future risk of exacerbations.

- Management strategies are not limited to pharmacologic treatments, and should be complemented by appropriate nonpharmacologic interventions.

Effective COPD management should be based on an individualised assessment to reduce both current symptoms and future risks of exacerbations (figure S1).

We propose personalisation of initiating and escalating/de-escalating treatments based on the level of symptoms and an individual's risk of exacerbations. The basis for these recommendations is partially based on evidence generated in RCTs. These recommendations are intended to support clinician decision-making. 
Identify and reduce exposure to risk factors

Cigarette smoking is the most commonly encountered and easily identifiable risk factor for COPD; smoking cessation should be continually encouraged for current smokers. Reduction of total personal exposure to occupational dusts, fumes, and gases, and to indoor and outdoor air pollutants, should be addressed.

\section{Treatment of stable COPD}

Pharmacologic treatment

Pharmacologic therapies can reduce symptoms, the risk and severity of exacerbations, and improve health status and exercise tolerance. The choice within each class depends on the availability of medication and the patient's response and preference (tables 5-7).

\section{Pharmacologic treatment algorithms}

A proposed model for the initiation, and then subsequent escalation and/or de-escalation of pharmacologic management according to the individualised assessment of symptoms and exacerbation risk is shown in figure 3. In past GOLD Reports, recommendations were only given for initial therapy. However, many COPD patients are already on treatment and return with persistent symptoms after initial therapy, or less commonly with resolution of some symptoms that may subsequently require less therapy. Therefore, we now suggest escalation and de-escalation strategies. The recommendations are based on available efficacy and safety data. We acknowledge that treatment escalation has not been systematically tested; trials of de-escalation are also limited and only include ICS. There is a lack of direct evidence supporting the therapeutic recommendations for patients in groups $\mathrm{C}$ and $\mathrm{D}$. These recommendations will be re-evaluated as additional data become available.

\section{Group A}

All Group A patients should be offered a bronchodilator to reduce breathlessness. This can be either a short or a long-acting bronchodilator based on the individual patient's preference. The bronchodilator should be continued if symptomatic benefit is noted.

\section{TABLE 5 Key points for the use of bronchodilators}

\section{LABAs and LAMAs are preferred over short-acting agents except for patients with only occasional} dyspnoea (evidence A)

Patients may be started on single long-acting bronchodilator therapy or dual long-acting bronchodilator therapy. In patients with persistent dyspnoea on one bronchodilator treatment should be escalated to two (evidence A).

Inhaled bronchodilators are recommended over oral bronchodilators (evidence A)

Theophylline is not recommended unless other long-term treatment bronchodilators are unavailable or unaffordable (evidence B)

LABA: long-acting $\beta_{2}$-agonist; LAMA: long-acting muscarinic antagonist.

\section{TABLE 6 Key points for the use of anti-inflammatory agents}

Long-term monotherapy with ICS is not recommended (evidence A)

Long-term treatment with ICS may be considered in association with LABAs for patients with a history of exacerbations despite appropriate treatment with long-acting bronchodilators (evidence A)

Long-term therapy with oral corticosteroids is not recommended (evidence Al

In patients with exacerbations despite LABA/ICS or LABA/LAMA/ICS, chronic bronchitis and severe to very severe airflow obstruction, the addition of a PDE4 inhibitor can be considered (evidence B)

In former smokers with exacerbations despite appropriate therapy, macrolides can be considered (evidence B)

Statin therapy is not recommended for prevention of exacerbations (evidence A)

Antioxidant mucolytics are recommended only in selected patients (evidence A)

ICS: inhaled corticosteroid; LABA: long-acting $\beta_{2}$-agonist; LAMA: long-acting muscarinic antagonist; PDE: phosphodiesterase. 
TABLE 7 Key points for the use of other pharmacologic treatments

Patients with severe hereditary $\alpha_{1}$-antitrypsin deficiency and established emphysema may be candidates for $\alpha_{1}$-antitrypsin augmentation therapy (evidence B)

Antitussives cannot be recommended (evidence C)

Drugs approved for primary pulmonary hypertension are not recommended for patients with pulmonary hypertension secondary to COPD (evidence B)

Low-dose long acting oral and parenteral opioids may be considered for treating dyspnoea in COPD patients with severe disease (evidence B)

COPD: chronic obstructive pulmonary disease.

Group B

Initial therapy should be a long acting bronchodilator. Long-acting bronchodilators are superior to short-acting bronchodilators taken intermittently $[104,219]$. There is no evidence to recommend one class of long-acting bronchodilators over another for symptom relief; the choice should depend on individual patient response.

For patients with persistent breathlessness on monotherapy [220] the use of two bronchodilators is recommended. For patients with severe breathlessness, initial therapy with two bronchodilators may be considered.

Group C

Initial therapy should be a single long-acting bronchodilator. In two head-to-head comparisons [110, 111] the LAMA tested superior to the LABA regarding exacerbation prevention, therefore we recommend initiating a LAMA in this group.

Patients with persistent exacerbations may benefit from adding a second long-acting bronchodilator (LABA/LAMA), or using LABA/ICS. As ICS increases the risk for developing pneumonia, our primary choice is LABA/LAMA.

Group D

We recommend initiating a LABA/LAMA combination because:

- In studies with patient reported outcomes as the primary endpoint, LABA/LAMA combinations showed superior results compared to a single bronchodilator.

- LABA/LAMA combination was superior to LABA/ICS combination in preventing exacerbations and improving other patient reported outcomes in Group D patients.

- Group D patients are at higher risk for pneumonia when receiving ICS treatment $[111,133]$.

If a single bronchodilator is initially chosen, a LAMA is preferred for exacerbation prevention based on comparison to LABAs.

LABA/ICS may be the first choice for initial therapy in some patients. These patients may have a history and/or findings suggestive of asthma-COPD overlap and/or high blood eosinophil counts.

In patients who develop additional exacerbations on LABA/LAMA therapy we suggest two alternative pathways:

- Escalation to LABA/LAMA/ICS.

- Switch to LABA/ICS. If LABA/ICS therapy does not positively impact exacerbations/symptoms, a LAMA can be added.

If patients treated with LABA/LAMA/ICS still have exacerbations the following options may be considered:

- Add roflumilast. This may be considered in patients with an FEV $1<50 \%$ predicted and chronic bronchitis [221], particularly if they experienced at least one hospitalisation for an exacerbation in the previous year [222].

- Add a macrolide in former smokers. The possibility of developing resistant organisms should be factored into the decision making.

- Stopping ICS. This recommendation is supported by data that shows an elevated risk of adverse effects (including pneumonia) and no significant harm from ICS withdrawal.

\section{Nonpharmacologic treatment}

Education and self-management

An individual patient's evaluation and risk assessment (e.g., exacerbations, patient's needs, preferences, and personal goals) should aid the design of personalised self-management. 

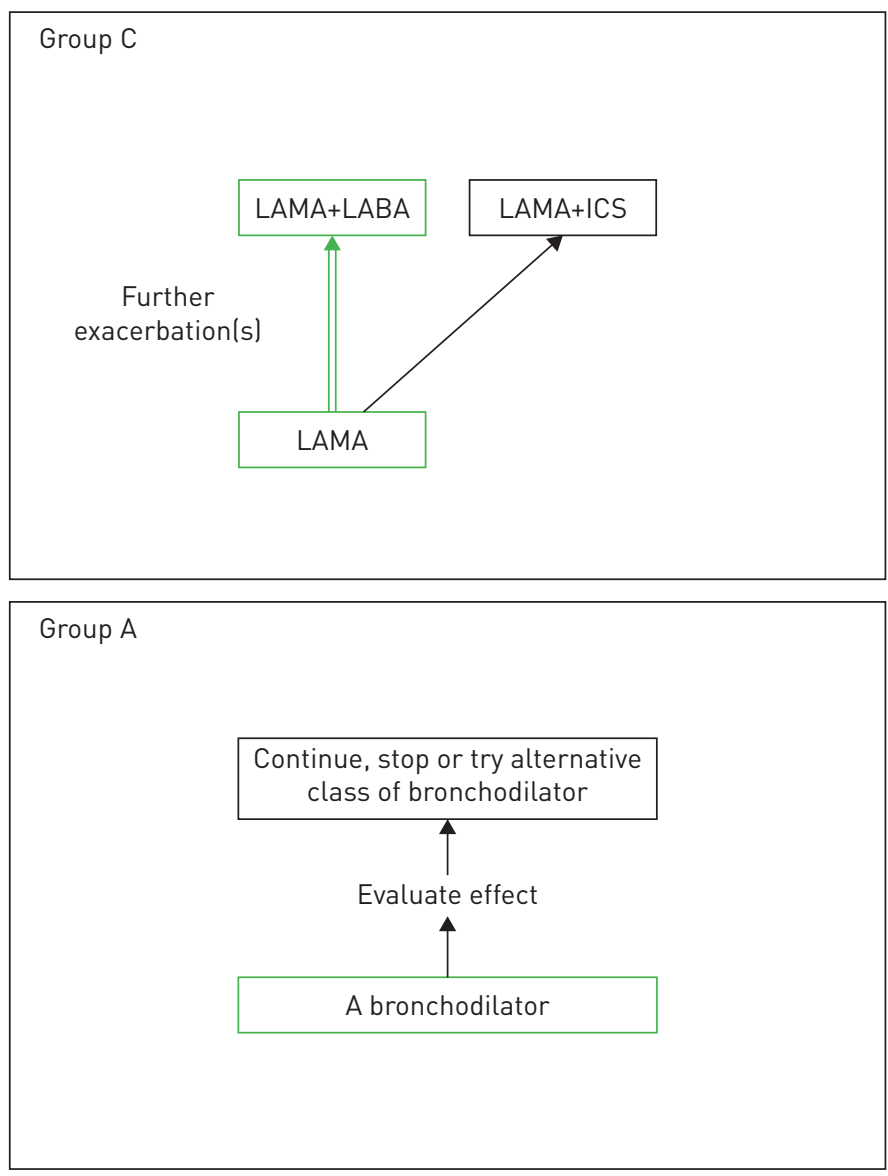

$\Longrightarrow$ : preferred treatment
Group D

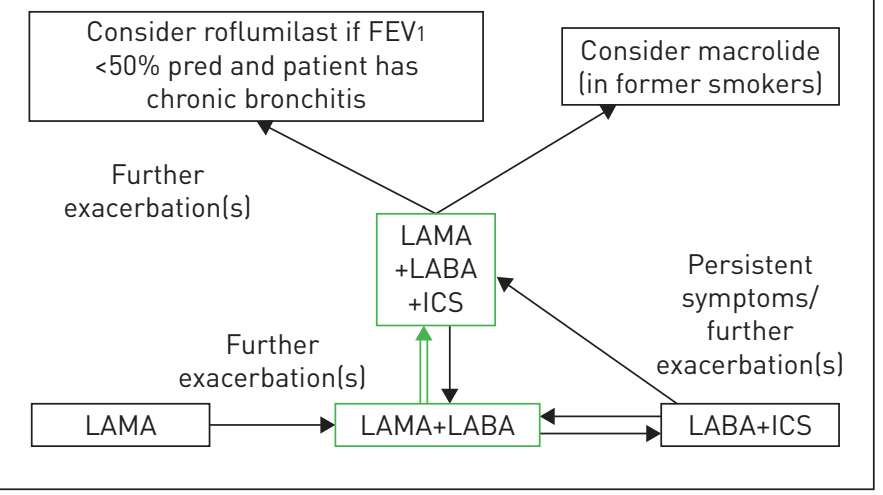

Group B

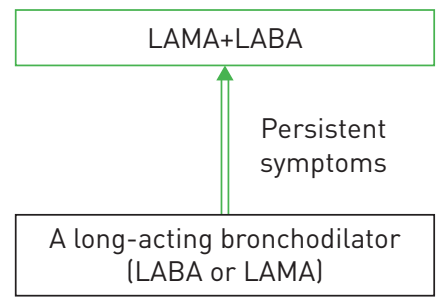

FIGURE 3 Pharmacologic treatment algorithms by Global Initiative for Chronic Obstructive Lung Disease grade. Highlighted boxes and arrows indicate preferred treatment pathways. In patients with a major discrepancy between the perceived level of symptoms and severity of airflow limitation, further evaluation is warranted. LAMA: long-acting muscarinic antagonist; LABA: long-acting $\beta_{2}$-agonist; ICS: inhaled corticosteroid; FEV1: forced expiratory volume in $1 \mathrm{~s}$.

Pulmonary rehabilitation programmes

Patients with high symptom burden and risk of exacerbations (groups B, C and D), should take part in a full rehabilitation programme that considers the individual's characteristics and comorbidities [182, 187, 223].

\section{Exercise training}

A combination of constant load or interval training with strength training provides better outcomes than either method alone [224]. Adding strength training to aerobic training is effective in improving strength, but does not improve health status or exercise tolerance [225]. Upper extremity exercise training improves arm strength and endurance and improves capacity for upper extremity activities [226].

\section{Self-management education}

An educational programme should include smoking cessation; basic information about COPD; aspects of medical treatment (respiratory medications and inhalation devices); strategies to minimise dyspnoea; advice about when to seek help; and possibly a discussion of advance directives and end-of-life issues.

\section{End-of-life and palliative care}

Patients should be informed that should they become critically ill, they or their family members may need to decide whether a course of intensive care is likely to achieve their personal goals of care. Simple, structured conversations about these possible scenarios should be discussed while patients are in their stable state [227].

\section{Nutritional support}

For malnourished patients with COPD nutritional supplementation is recommended. 
Vaccination

Influenza vaccination is recommended for all patients with COPD. The pneumococcal vaccinations PCV13 and PPSV23 are recommended for all patients $>65$ years of age. PPSV23 is also recommended for younger COPD patients with significant comorbid conditions including chronic heart or lung disease [228].

\section{Oxygen therapy}

Long-term oxygen therapy is indicated for stable patients who have:

- arterial oxygen tension $\left(\mathrm{PaO}_{2}\right)$ at or below $7.3 \mathrm{kPa}(55 \mathrm{mmHg})$ or arterial oxygen saturation $\left(\mathrm{SaO}_{2}\right)$ at or below $88 \%$, with or without hypercapnia confirmed twice over a three-week period; or

- $\mathrm{PaO}_{2}$ between $7.3 \mathrm{kPa}(55 \mathrm{mmHg})$ and $8.0 \mathrm{kPa}(60 \mathrm{mmHg})$, or $\mathrm{SaO}_{2}$ of $88 \%$, if there is evidence of pulmonary hypertension, peripheral oedema suggesting congestive cardiac failure, or polycythaemia (haematocrit $>55 \%$ ).

\section{Ventilatory support}

NIV is occasionally used in patients with stable very severe COPD. NIV may be considered in a selected group of patients, particularly those with pronounced daytime hypercapnia and recent hospitalisation, although contradictory evidence exists regarding its effectiveness [229]. In patients with both COPD and OSA continuous positive airway pressure is indicated [204].

\section{Interventional bronchoscopy and surgery}

- In selected patients with heterogeneous or homogenous emphysema and significant hyperinflation refractory to optimised medical care, surgical or bronchoscopic modes of lung volume reduction (e.g., endobronchial one-way valves or lung coils) may be considered [230].

- In selected patients with a large bulla, surgical bullectomy may be considered.

- In selected patients with very severe COPD and without relevant contraindications, lung transplantation may be considered.

Choosing bronchoscopic lung reduction or LVRS to treat hyperinflation in a patient with emphysema depends on a number of factors that include: the extent and pattern of emphysema identified on HRCT; the presence of interlobar collateral ventilation measured by fissure integrity on HRCT or physiological assessment (endoscopic balloon occlusion and flow assessment); local proficiency in the performance of the procedures; and patient and provider preferences. An algorithm depicting the various interventions based on radiological and physiological features is shown in figure 4.

Criteria for referral for lung transplantation include COPD with progressive disease, not a candidate for endoscopic or surgical lung volume reduction, BODE index of 5-6, carbon dioxide tension $>50 \mathrm{mmHg}$ or

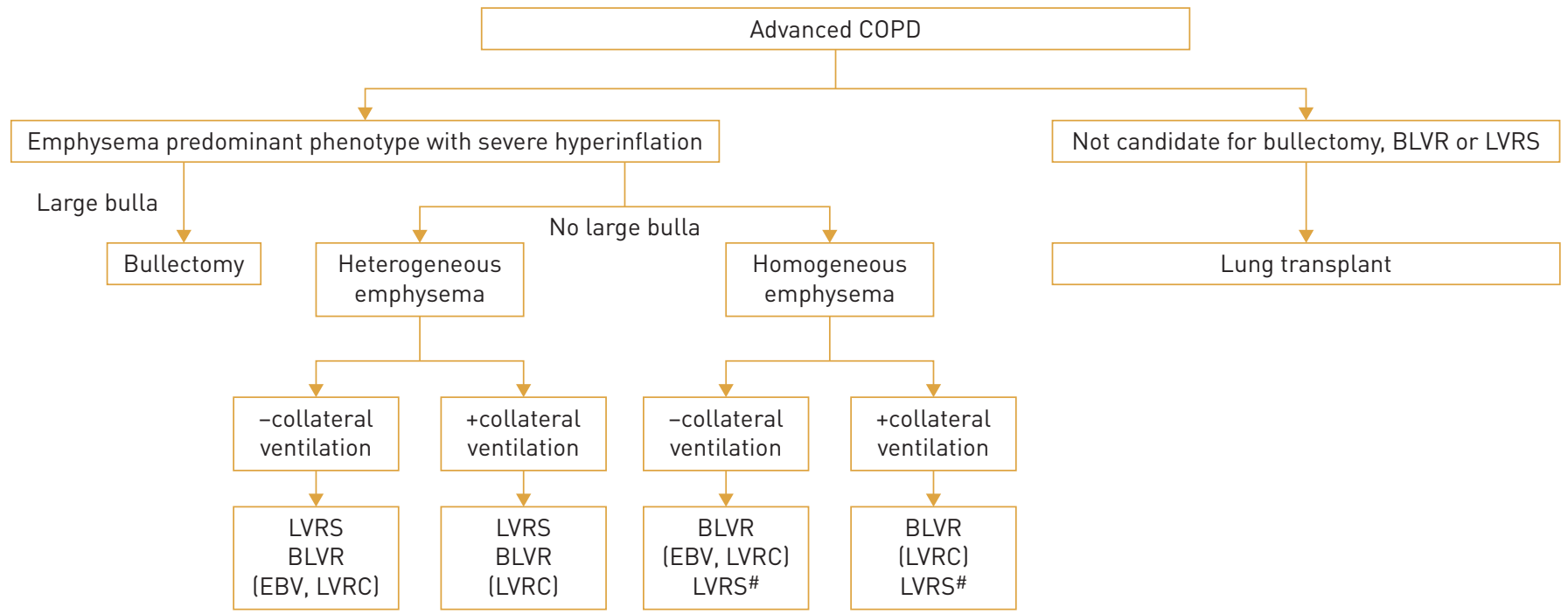

FIGURE 4 Interventional bronchoscopic and surgical treatments for chronic obstructive pulmonary disease (COPD). Overview of various therapies used to treat patients with COPD and emphysema worldwide. Note that not all therapies are approved for clinical care in all countries.

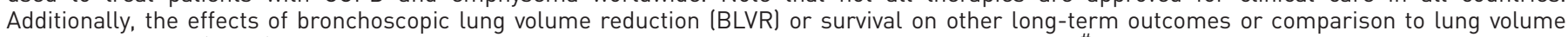
reduction surgery (LVRS) are unknown. EBV: endobronchial valve; LVRC: lung volume reduction coil. ${ }^{\#}$ : at some but not all centres. 
$6.6 \mathrm{kPa}$ and/or $\mathrm{PaO}_{2}<60 \mathrm{mmHg}$ or $8 \mathrm{kPa}$, and $\mathrm{FEV} 1<25 \%$ predicted [231]. Recommended criteria for listing include one of the following: BODE index $>7, \mathrm{FEV}_{1}<15-20 \%$ predicted, three or more severe exacerbations during the preceding year, one severe exacerbation with acute hypercapnic respiratory failure, or moderate to severe pulmonary hypertension [231, 232].

Key points for the use of nonpharmacologic treatments are summarised in table S9.

\section{Monitoring and follow-up}

Routine follow-up of COPD patients is essential. Symptoms, exacerbations and objective measures of airflow limitation should be monitored to determine when to modify management and to identify any complications and/or comorbidities that may develop. In order to adjust therapy appropriately as the disease progresses, each follow-up visit should include a discussion of the current therapeutic regimen. Symptoms that indicate worsening or development of another comorbid condition should be evaluated and treated.

\section{Management of exacerbations}

\section{Key points}

- An exacerbation of COPD is an acute worsening of respiratory symptoms that results in additional therapy.

- Exacerbations can be precipitated by several factors. The most common causes are respiratory tract infections.

- The goal for treatment of exacerbations is to minimise the negative impact of the current exacerbation and to prevent subsequent events.

- Short-acting inhaled $\beta_{2}$-agonists, with or without short-acting anticholinergics, are recommended as the initial bronchodilators to treat an acute exacerbation.

- Maintenance therapy with long-acting bronchodilators should be initiated as soon as possible before hospital discharge.

- Systemic corticosteroids improve lung function (FEV1), oxygenation and shorten recovery time and hospitalisation duration.

- Antibiotics, when indicated, shorten recovery time, and reduce the risk of early relapse or treatment failure, and hospitalisation duration.

- Methylxanthines are not recommended owing to side-effects.

- Non-invasive mechanical ventilation should be the first mode of ventilation used to treat acute respiratory failure.

- Following an exacerbation, appropriate measures for exacerbation prevention should be initiated.

Exacerbations are important events in the management of COPD because they negatively impact health status, rates of hospitalisation and readmission, and disease progression [237, 238]. COPD exacerbations are complex events usually associated with increased airway inflammation, increased mucus production and marked gas trapping. Increased dyspnoea is the key symptom of an exacerbation. Other symptoms include increased sputum purulence and volume, together with increased cough and wheeze [239]. As comorbidities are common in COPD patients, exacerbations must be differentiated from acute coronary syndrome, worsening congestive heart failure, pulmonary embolism and pneumonia.

COPD exacerbations are classified as:

- Mild (treated with short-acting bronchodilators (SABDs) only),

- Moderate (treated with SABDs plus antibiotics and/or oral corticosteroids) or

- Severe (patient requires hospitalisation or visits the emergency room). Severe exacerbations may be associated with acute respiratory failure.

Exacerbations are mainly triggered by respiratory viral infections although bacterial infections and environmental factors may also initiate and/or amplify these events [236].

Exacerbations can be associated with increased sputum production and, if purulent, increased bacteria may be found in the sputum $[235,237,238]$. Some evidence supports the concept that eosinophils are increased in the airways, lung, and blood in a significant proportion of patients with COPD. Exacerbations associated with an increase in sputum or blood eosinophils may be more responsive to systemic steroids [239] although more prospective data are needed [239].

Symptoms usually last between 7 to 10 days during an exacerbation, but some events may last longer. At 8 weeks, $20 \%$ of patients have not recovered to their pre-exacerbation state [240]. COPD exacerbations increase susceptibility to additional events [59, 245]. 
COPD patients susceptible to frequent exacerbations (defined as $\geqslant 2$ exacerbations per year) have worse health status and morbidity than patients with less frequent exacerbations [234]. Other factors associated with an increased risk of acute exacerbations and/or severity of exacerbations include an increase in the ratio of the pulmonary artery to aorta cross sectional dimension (i.e., ratio $>1$ ) [242], a greater percentage of emphysema or airway wall thickness [243] measured by chest CT imaging and the presence of chronic bronchitis $[244,248]$.

\section{Treatment options}

Treatment setting

The goals of exacerbation treatment are to minimise the negative impact of the current exacerbation, and to prevent the development of subsequent events [246]. Depending on the severity of an exacerbation and/ or the severity of the underlying disease, an exacerbation can be managed in either the outpatient or inpatient setting. More than $80 \%$ of exacerbations are managed on an outpatient basis with bronchodilators, corticosteroids, and antibiotics [59, 247, 248].

The indications for hospitalisation during a COPD exacerbation are shown in table S10. When patients with a COPD exacerbation come to the emergency department, they should be given supplemental oxygen and assessed to determine whether the exacerbation is life-threatening and requires consideration for NIV and intensive care unit (ICU) or respiratory unit hospitalisation.

Long-term prognosis following hospitalisation for COPD exacerbation is poor; the 5 -year mortality rate is about 50\% [249]. Factors associated with poor outcomes include older age, lower BMI, comorbidities (e.g., cardiovascular disease or lung cancer), previous hospitalisations for COPD exacerbations, clinical severity of the index exacerbation, and need for long-term oxygen therapy at discharge [250, 251]. Patients with a higher prevalence and severity of respiratory symptoms, poorer quality of life, worse lung function, lower exercise capacity, lower lung density and thickened bronchial walls on CT scan are at increased mortality risk following an acute exacerbation [252].

Key points for the management of all exacerbations are given in table 8.

\section{Pharmacologic treatment}

The most commonly used classes of medications for COPD exacerbations are bronchodilators, corticosteroids, and antibiotics.

\section{Bronchodilators}

Short-acting inhaled $\beta_{2}$-agonists, with or without short-acting anticholinergics, are the initial bronchodilators recommended for acute treatment of exacerbations [253, 254]. There are no significant differences in FEV1 when using metered dose inhalers (with or without a spacer device) or nebulisers to deliver the agent [255], although the latter may be an easier delivery method for sicker patients. Intravenous methylxanthines are not recommended owing to side-effects [256, 257].

\section{Glucocorticoids}

Systemic glucocorticoids in COPD exacerbations shorten recovery time and improve FEV1. They also improve oxygenation [258-261], the risk of early relapse, treatment failure [262], and the length of hospitalisation [258, 260, 263]. A dose of $40 \mathrm{mg}$ prednisone per day for 5 days is recommended [264].

\section{TABLE 8 Key points for the management of exacerbations}

Short-acting inhaled $\beta_{2}$-agonists, with or without short-acting anticholinergics, are recommended as the initial bronchodilators to treat an acute exacerbation (evidence $\mathrm{C}$ )

Systemic corticosteroids improve lung function (FEV 1 ), oxygenation and shorten recovery time and hospitalisation duration. Duration of therapy should not be more than 5-7 days (evidence A).

Antibiotics, when indicated, can shorten recovery time, reduce the risk of early relapse, treatment failure, and hospitalisation duration. Duration of therapy should be 5-7 days (evidence B).

Methylxanthines are not recommended due to increased side effect profiles (evidence B)

NIV should be the first mode of ventilation used in COPD patients with acute respiratory failure who have no absolute contraindication because it improves gas exchange, reduces work of breathing and the need for intubation, decreases hospitalisation duration and improves survival (evidence A)

FEV1: forced expiratory volume in $1 \mathrm{~s}$; NIV: non-invasive ventilation; COPD: chronic obstructive pulmonary disease. 
Therapy with oral prednisolone is equally effective to intravenous administration [265]. Glucocorticoids may be less efficacious to treat exacerbations in patients with lower blood eosinophil levels $[59,239,266]$.

\section{Antibiotics}

The use of antibiotics in exacerbations remains controversial [267-269]. Evidence supports the use of antibiotics in patients with exacerbations and increased sputum purulence $[268,269]$. One review reported that antibiotics reduce the risk of short-term mortality by $77 \%$, treatment failure by $53 \%$ and sputum purulence by $44 \%$ [270]. Procalcitonin-guided antibiotic treatment may reduce antibiotic exposure and side-effects with the same clinical efficacy $[271,272]$. A study in patients with exacerbations requiring mechanical ventilation (invasive or non-invasive) reported increased mortality and a higher incidence of secondary nosocomial pneumonia when antibiotics were not given [273]. Antibiotics should be given to patients with acute exacerbations who have three cardinal symptoms: increase in dyspnoea, sputum volume, and sputum purulence; have two of the cardinal symptoms, if increased purulence of sputum is one of the two symptoms; or require mechanical ventilation (invasive or noninvasive) $[235,236]$. The recommended length of antibiotic therapy is 5-7 days [274].

Antibiotic choice should be based on the local bacterial resistance pattern. Usual initial empirical treatment is an aminopenicillin with clavulanic acid, a macrolide, or a tetracycline. In patients with frequent exacerbations, severe airflow limitation $[275,276]$, and/or exacerbations requiring mechanical ventilation [277], cultures from sputum or other materials from the lung should be performed to identify the presence of resistant pathogens. Administration route depends on the patient's ability to eat and the pharmacokinetics of the antibiotic.

Respiratory support

Oxygen therapy

Supplemental oxygen should be titrated to improve hypoxaemia with a target saturation of 88-92\% [278]. Once oxygen is started, blood gases should be checked to ensure satisfactory oxygenation without carbon dioxide retention and/or worsening acidosis.

\section{Ventilatory support}

Some patients require admission to the ICU. Admission of patients with severe exacerbations to intermediate or special respiratory care units may be appropriate if adequate personnel skills and equipment exist to manage acute respiratory failure.

\section{Noninvasive mechanical ventilation}

NIV is preferred over invasive ventilation as the initial mode of ventilation to treat acute respiratory failure in patients hospitalised for acute exacerbations of COPD. NIV has been studied in RCTs showing a success rate of $80-85 \%$ [279-283]. Mortality and intubation rates are reduced by NIV [279, 284-286].

Invasive mechanical ventilation

The indication for initiating invasive mechanical ventilation during an exacerbation includes failure of an initial trial of NIV [287]. In patients who fail NIV as initial therapy and receive invasive ventilation as subsequent rescue therapy, morbidity, hospital length of stay and mortality are greater [282].

\section{Hospital discharge and follow-up}

Lack of spirometric assessment and arterial blood gas analysis have been associated with re-hospitalisation and mortality [288]. Mortality relates to patient age, the presence of acidotic respiratory failure, the need for ventilatory support and comorbidities including anxiety and depression [289].

The introduction of care bundles at hospital discharge to include education, optimisation of medication, supervision and correction of inhaler technique, assessment and optimal management of comorbidities, early rehabilitation, telemonitoring and continued patient contact have been investigated [290]. There is insufficient data that they influence readmission rates, short-term mortality $[288,289,291,292]$ or cost-effectiveness [289].

Early follow-up (<30 days) following discharge should be undertaken when possible and has been related to less exacerbation-related readmissions $[184,293]$. Early follow-up permits a careful review of discharge therapy and an opportunity to make changes in therapy. Patients not attending early follow-up have increased 90-day mortality.

Additional follow-up at 3 months is recommended to ensure return to a stable state and review of patient's symptoms, lung function (by spirometry), and when possible the assessment of prognosis using multiple 
scoring systems such as BODE [293, 294]. An assessment of the presence and management of comorbidities should also be undertaken (table S11) [295].

Prevention of exacerbations

After an acute exacerbation, measures for prevention of further exacerbations should be initiated (table S12).

\section{COPD and comorbidities}

\section{Key points}

- COPD often coexists with other diseases (comorbidities) that may significantly impact patient outcomes.

- The presence of comorbidities should not alter COPD treatment and comorbidities should be treated per usual standards regardless of the presence of COPD.

- When COPD is part of a multi-morbidity care plan, attention should be directed to ensure simplicity of treatment and minimise polypharmacy.

COPD often coexists with other diseases (comorbidities) that may have a significant impact on prognosis $[63,296-302]$. Some of these arise independently of COPD whereas others may be causally related, either with shared risk factors, or by one disease increasing the risk or compounding the severity of the other [303]. Management of the COPD patient must include identification and treatment of its comorbidities; the most common in COPD are outlined below.

\section{Cardiovascular disease}

Heart failure

The prevalence of systolic or diastolic heart failure in COPD patients ranges from 20\% to 70\% [304]. Unrecognised heart failure may mimic or accompany acute exacerbations of COPD; $40 \%$ of COPD patients that are mechanically ventilated because of hypercapnic respiratory failure have evidence of left ventricular dysfunction $[305,306]$. Treatment with $\beta_{1}$-blockers improves survival in chronic heart failure and is recommended. Selective $\beta_{1}$-blockers should be used [307].

\section{Ischaemic heart disease}

There is an increased risk of myocardial damage in patients with concomitant ischaemic heart disease who have an acute exacerbation of COPD. Patients who demonstrate abnormal cardiac troponins are at an increased risk of adverse outcomes including short-term (30-day) and long-term mortality [308].

\section{Arrhythmias}

Cardiac arrhythmias are common in COPD and vice versa. Atrial fibrillation is frequent and directly associated with FEV1. Bronchodilators have been previously described as potentially pro-arrhythmic agents [309, 310]; however, evidence suggests an overall acceptable safety profile for LABA [311] and anticholinergic drugs (and ICS) [101, 113, 248, 312-316].

\section{Peripheral vascular disease}

In a large cohort of patients with COPD of all degrees of severity, $8.8 \%$ were diagnosed with peripheral artery disease (PAD), which was higher than the prevalence in non-COPD controls (1.8\%) [317]. COPD patients with PAD reported a worse functional capacity and worse health status compared to those without PAD.

\section{Hypertension}

Hypertension is likely to be the most frequently occurring comorbidity in COPD and may have implications for prognosis [303, 318].

\section{Osteoporosis}

Osteoporosis is often associated with emphysema [319, 320], decreased BMI [321] and low fat-free mass [322]. Low bone mineral density and fractures are common in COPD patients even after adjustment for steroid use, age, pack-years of smoking, current smoking and exacerbations [323, 324]. An association between ICS and fractures has been found in pharmaco-epidemiological studies. Systemic corticosteroids significantly increase the risk of osteoporosis. 
Anxiety and depression

Anxiety and depression are both associated with a poor prognosis [325, 326].

Lung cancer

The association between emphysema and lung cancer is stronger than between airflow limitation and lung cancer [327-329]. Increased age and greater smoking history further increase risk [330]. Two studies of low-dose chest computed tomography (LDCT) screening report improved survival in subjects aged 55-74 years, current smokers or those who quit within the previous 15 years, with a smoking history of at least 30 pack-years [331, 332]. LDCT is now recommended in the USA for patients meeting these demographics; however, this is not a worldwide practice.

\section{Metabolic syndrome and diabetes}

Metabolic syndrome and diabetes are more frequent in COPD and the latter is likely to affect prognosis [297]. The prevalence of metabolic syndrome has been estimated to be $>30 \%$ [332].

\section{Gastro-oesophageal reflux}

Gastro-oesophageal reflux is an independent risk factor for exacerbations and is associated with worse health status $[59,334,335]$.

\section{Bronchiectasis}

Bronchiectasis is associated with longer exacerbations [336] and increased mortality [295].

\section{Obstructive sleep apnoea}

Patients with "overlap syndrome" (COPD and OSA) have a worse prognosis compared with COPD or OSA. Apnoeic events in patients with OSA and COPD have more profound hypoxaemia and more cardiac arrhythmias [337] and are more likely to develop daytime pulmonary hypertension [338, 339] than patients with just OSA or COPD alone.

\section{References}

1 Woodruff PG, Barr RG, Bleecker E, et al. Clinical significance of symptoms in smokers with preserved pulmonary function. $N$ Engl J Med 2016; 374: 1811-1821.

2 Regan EA, Lynch DA, Curran-Everett D, et al. Clinical and radiologic disease in smokers with normal spirometry. JAMA Intern Med 2015; 175: 1539-1549.

3 Lamprecht B, McBurnie MA, Vollmer WM, et al. COPD in never smokers: results from the population-based burden of obstructive lung disease study. Chest 2011; 139: 752-763.

4 Thomsen M, Nordestgaard BG, Vestbo J, et al. Characteristics and outcomes of chronic obstructive pulmonary disease in never smokers in Denmark: a prospective population study. Lancet Respir Med 2013; 1: 543-550.

5 Barker DJ, Godfrey KM, Fall C, et al. Relation of birth weight and childhood respiratory infection to adult lung function and death from chronic obstructive airways disease. BMJ 1991; 303: 671-675.

6 Todisco T, de Benedictis FM, Iannacci L, et al. Mild prematurity and respiratory functions. Eur J Pediatr 1993; 152: $55-58$

7 Stern DA, Morgan WJ, Wright AL, et al. Poor airway function in early infancy and lung function by age 22 years: a non-selective longitudinal cohort study. Lancet 2007; 370: 758-764.

8 Lawlor DA, Ebrahim S, Davey Smith G. Association of birth weight with adult lung function: findings from the British Women's Heart and Health Study and a meta-analysis. Thorax 2005; 60: 851-858.

9 Kohansal R, Martinez-Camblor P, Agusti A, et al. The natural history of chronic airflow obstruction revisited: an analysis of the Framingham offspring cohort. Am J Respir Crit Care Med 2009; 180: 3-10.

10 Raad D, Gaddam S, Schunemann HJ, et al. Effects of water-pipe smoking on lung function: a systematic review and meta-analysis. Chest 2011; 139: 764-774.

11 She J, Yang P, Wang Y, et al. Chinese water-pipe smoking and the risk of COPD. Chest 2014; 146: 924-931.

12 Gunen H, Tarraf H, Nemati A, et al. Waterpipe tobacco smoking. Tuberk Toraks 2016; 64: 94-96.

13 Tan WC, Lo C, Jong A, et al. Marijuana and chronic obstructive lung disease: a population-based study. CMAJ 2009; 180: 814-820.

14 Yin P, Jiang CQ, Cheng KK, et al. Passive smoking exposure and risk of COPD among adults in China: the Guangzhou Biobank Cohort Study. Lancet 2007; 370: 751-757.

15 Tager IB, Ngo L, Hanrahan JP. Maternal smoking during pregnancy. Effects on lung function during the first 18 months of life. Am J Respir Crit Care Med 1995; 152: 977-983.

16 Paulin LM, Diette GB, Blanc PD, et al. Occupational exposures are associated with worse morbidity in patients with chronic obstructive pulmonary disease. Am J Respir Crit Care Med 2015; 191: 557-565.

17 Eisner MD, Anthonisen N, Coultas D, et al. An official American Thoracic Society public policy statement: Novel risk factors and the global burden of chronic obstructive pulmonary disease. Am J Respir Crit Care Med 2010; 182: 693-718

18 Orozco-Levi M, Garcia-Aymerich J, Villar J, et al. Wood smoke exposure and risk of chronic obstructive pulmonary disease. Eur Respir J 2006; 27: 542-546.

19 Gan WQ, FitzGerald JM, Carlsten C, et al. Associations of ambient air pollution with chronic obstructive pulmonary disease hospitalization and mortality. Am J Respir Crit Care Med 2013; 187: 721-727.

20 Ezzati M. Indoor air pollution and health in developing countries. Lancet 2005; 366: 104-106. 
Zhou Y, Zou Y, Li X, et al. Lung function and incidence of chronic obstructive pulmonary disease after improved cooking fuels and kitchen ventilation: a 9-year prospective cohort study. PLoS Med 2014; 11: e1001621.

Silva GE, Sherrill DL, Guerra S, et al. Asthma as a risk factor for COPD in a longitudinal study. Chest 2004; 126 : $59-65$.

Rijcken B, Schouten JP, Weiss ST, et al. The relationship of nonspecific bronchial responsiveness to respiratory symptoms in a random population sample. Am Rev Respir Dis 1987; 136: 62-68.

Hospers JJ, Postma DS, Rijcken B, et al. Histamine airway hyper-responsiveness and mortality from chronic obstructive pulmonary disease: a cohort study. Lancet 2000; 356: 1313-1317.

Tashkin DP, Altose MD, Connett JE, et al. Methacholine reactivity predicts changes in lung function over time in smokers with early chronic obstructive pulmonary disease. The Lung Health Study Research Group. Am J Respir Crit Care Med 1996; 153(6 Pt 1): 1802-1811.

de Marco R, Accordini S, Marcon A, et al. Risk factors for chronic obstructive pulmonary disease in a European cohort of young adults. Am J Respir Crit Care Med 2011; 183: 891-897.

Drummond MB, Kirk GD. HIV-associated obstructive lung diseases: insights and implications for the clinician. Lancet Respir Med 2014; 2: 583-592.

Menezes AM, Hallal PC, Perez-Padilla R, et al. Tuberculosis and airflow obstruction: evidence from the PLATINO study in Latin America. Eur Respir J 2007; 30: 1180-1185.

Jordan TS, Spencer EM, Davies P. Tuberculosis, bronchiectasis and chronic airflow obstruction. Respirology 2010; 15: 623-628.

Byrne AL, Marais BJ, Mitnick CD, et al. Tuberculosis and chronic respiratory disease: a systematic review. Int $J$ Infect Dis 2015; 32: 138-146.

Buist AS, McBurnie MA, Vollmer WM, et al. International variation in the prevalence of COPD (the BOLD Study): a population-based prevalence study. Lancet 2007; 370: 741-750.

Miravitlles M, Worth H, Soler Cataluna JJ, et al. Observational study to characterise 24-hour COPD symptoms and their relationship with patient-reported outcomes: results from the ASSESS study. Respir Res 2014; 15: 122.

Elliott MW, Adams L, Cockcroft A, et al. The language of breathlessness. Use of verbal descriptors by patients with cardiopulmonary disease. Am Rev Respir Dis 1991; 144: 826-832.

Medical Research Council Committee on the Aetiology of Chronic Bronchitis. Definition and classification of chronic bronchitis for clinical and epidemiological purposes. A report to the Medical Research Council by their Committee on the Aetiology of Chronic Bronchitis. Lancet 1965; 1: 775-779.

von Haehling S, Anker SD. Cachexia as a major underestimated and unmet medical need: facts and numbers. J Cachexia Sarcopenia Muscle 2010; 1: 1-5.

Schols AM, Soeters PB, Dingemans AM, et al. Prevalence and characteristics of nutritional depletion in patients with stable COPD eligible for pulmonary rehabilitation. Am Rev Respir Dis 1993; 147: 1151-1156.

Holleman DR Jr, Simel DL. Does the clinical examination predict airflow limitation? JAMA 1995; 273: 313-319.

Kesten S, Chapman KR. Physician perceptions and management of COPD. Chest 1993; 104: 254-258.

van Dijk W, Tan W, Li P, et al. Clinical relevance of fixed ratio vs lower limit of normal of FEV $1 / \mathrm{FVC}$ in COPD: patient-reported outcomes from the CanCOLD cohort. Ann Fam Med 2015; 13: 41-48.

Guder G, Brenner S, Angermann CE, et al. GOLD or lower limit of normal definition? A comparison with expert-based diagnosis of chronic obstructive pulmonary disease in a prospective cohort-study. Respir Res 2012; 13: 13. Vaz Fragoso CA, McAvay G, Van Ness PH, et al. Phenotype of normal spirometry in an aging population. Am J Respir Crit Care Med 2015; 192: 817-825.

Vaz Fragoso CA, McAvay G, Van Ness PH, et al. Phenotype of spirometric impairment in an aging population. Am J Respir Crit Care Med 2016; 193: 727-735.

Albert P, Agusti A, Edwards L, et al. Bronchodilator responsiveness as a phenotypic characteristic of established chronic obstructive pulmonary disease. Thorax 2012; 67: 701-708.

Hansen JE, Porszasz J. Counterpoint: Is an increase in FEV1 and/or FVC $\geqslant 12 \%$ of control and $\geqslant 200 \mathrm{~mL}$ the best way to assess positive bronchodilator response? No. Chest 2014; 146: 538-541.

Hill K, Goldstein RS, Guyatt GH, et al. Prevalence and underdiagnosis of chronic obstructive pulmonary disease among patients at risk in primary care. CMAJ 2010; 182: 673-678.

Lopez Varela MV, Montes de Oca M, Rey A, et al. Development of a simple screening tool for opportunistic COPD case finding in primary care in Latin America: The PUMA study. Respirology 2016; 21: 1227-1234.

Dirven JA, Tange HJ, Muris JW, et al. Early detection of COPD in general practice: implementation, workload and socioeconomic status. A mixed methods observational study. Prim Care Respir J 2013; 22: 338-343.

Fletcher CM. Standardised questionnaire on respiratory symptoms: a statement prepared and approved by the MRC Committee on the Aetiology of Chronic Bronchitis (MRC breathlessness score). BMJ 1960; 2: 1662.

Bestall JC, Paul EA, Garrod R, et al. Usefulness of the Medical Research Council (MRC) dyspnoea scale as a measure of disability in patients with chronic obstructive pulmonary disease. Thorax 1999; 54: 581-586.

Sundh J, Janson C, Lisspers K, et al. The Dyspnoea, Obstruction, Smoking, Exacerbation (DOSE) index is predictive of mortality in COPD. Prim Care Respir J 2012; 21: 295-301.

Nishimura K, Izumi T, Tsukino M, et al. Dyspnea is a better predictor of 5 -year survival than airway obstruction in patients with COPD. Chest 2002; 121: 1434-1440.

Jones PW. Health status measurement in chronic obstructive pulmonary disease. Thorax 2001; 56: 880-887.

Guyatt GH, Berman LB, Townsend M, et al. A measure of quality of life for clinical trials in chronic lung disease. Thorax 1987; 42: 773-778.

Jones PW, Quirk FH, Baveystock CM, et al. A self-complete measure of health status for chronic airflow limitation. The St. George's Respiratory Questionnaire. Am Rev Respir Dis 1992; 145: 1321-1327.

Agusti A, Calverley PM, Celli B, et al. Characterisation of COPD heterogeneity in the ECLIPSE cohort. Respir Res 2010; 11: 122.

Nishimura K, Mitsuma S, Kobayashi A, et al. COPD and disease-specific health status in a working population. Respir Res 2013; 14: 61.

Miravitlles M, Soriano J, Garcia-Rio F, et al. Prevalence of COPD in Spain: impact of undiagnosed COPD on quality of life and daily life activities. Thorax 2009; 64: 863-868. 
Jones PW, Tabberer M, Chen WH. Creating scenarios of the impact of COPD and their relationship to COPD Assessment Test (CAT) scores. BMC Pulm Med 2011; 11: 42.

Hurst JR, Vestbo J, Anzueto A, et al. Susceptibility to exacerbation in chronic obstructive pulmonary disease. N Engl J Med 2010; 363: 1128-1138.

Soler-Cataluna JJ, Martinez-Garcia MA, Roman Sanchez P, et al. Severe acute exacerbations and mortality in patients with chronic obstructive pulmonary disease. Thorax 2005; 60: 925-931.

Pascoe S, Locantore N, Dransfield M, et al. Blood eosinophil counts, exacerbations, and response to the addition of inhaled fluticasone furoate to vilanterol in patients with chronic obstructive pulmonary disease: a secondary analysis of data from two parallel randomised controlled trials. Lancet Respir Med 2015; 3: 435-442.

Siddiqui SH, Guasconi A, Vestbo J, et al. Blood eosinophils: a biomarker of response to extrafine beclomethasone/ formoterol in chronic obstructive pulmonary disease. Am J Respir Crit Care Med 2015; 192: 523-525.

Soriano JB, Visick GT, Muellerova H, et al. Patterns of comorbidities in newly diagnosed COPD and asthma in primary care. Chest 2005; 128: 2099-2107.

National Institute for Health and Care Excellence. Multimorbidity: clinical assessment and management, in press. 2016. www.nice.org.uk/guidance/indevelopment/gid-cgwave0704/documents Date last accessed: August 1, 2016.

Vanfleteren LE, Spruit MA, Groenen M, et al. Clusters of comorbidities based on validated objective measurements and systemic inflammation in patients with chronic obstructive pulmonary disease. Am J Respir Crit Care Med 2013; 187: 728-735.

Soriano JB, Lamprecht B, Ramirez AS, et al. Mortality prediction in chronic obstructive pulmonary disease comparing the GOLD 2007 and 2011 staging systems: a pooled analysis of individual patient data. Lancet Respir Med 2015; 3: 443-450.

Goossens LM, Leimer I, Metzdorf N, et al. Does the 2013 GOLD classification improve the ability to predict lung function decline, exacerbations and mortality: a post-hoc analysis of the 4-year UPLIFT trial. BMC Pulm Med 2014; 14: 163.

Kim J, Yoon HI, Oh YM, et al. Lung function decline rates according to GOLD group in patients with chronic obstructive pulmonary disease. Int J Chron Obstruct Pulmon Dis 2015; 10: 1819-1827.

Han MK, Muellerova H, Curran-Everett D, et al. GOLD 2011 disease severity classification in COPDGene: a prospective cohort study. Lancet Respir Med 2013; 1: 43-50.

WHO meeting participants. Alpha 1-antitrypsin deficiency: memorandum from a WHO meeting. Bull World Health Organ 1997; 75: 397-415.

Celli BR, Cote CG, Marin JM, et al. The body-mass index, airflow obstruction, dyspnea, and exercise capacity index in chronic obstructive pulmonary disease. N Engl J Med 2004; 350: 1005-1012.

ones RC, Donaldson GC, Chavannes NH, et al. Derivation and validation of a composite index of severity in chronic obstructive pulmonary disease: the DOSE Index. Am J Respir Crit Care Med 2009; 180: 1189-1195.

Puhan MA, Garcia-Aymerich J, Frey M, et al. Expansion of the prognostic assessment of patients with chronic obstructive pulmonary disease: the updated BODE index and the ADO index. Lancet 2009; 374: 704-711.

van Eerd EA, van der Meer RM, van Schayck OC, et al. Smoking cessation for people with chronic obstructive pulmonary disease. Cochrane Database Syst Rev 2016; CD010744.

The tobacco use and dependence clinical practice guideline panel, staff, and consortium representatives. A clinical practice guideline for treating tobacco use and dependence. JAMA 2000; 28: 3244-3254.

van der Meer RM, Wagena EJ, Ostelo RW, et al. Smoking cessation for chronic obstructive pulmonary disease. Cochrane Database Syst Rev 2003; 2: CD002999.

A clinical practice guideline for treating tobacco use and dependence: 2008 update. A U.S. Public Health Service report. Am J Prev Med 2008; 35: 158-176.

McNeill A, Brose LS, Calder R, et al. E-cigarettes: an evidence update. A report commissioned by Public Health England. London, Public Health England, 2015.

McRobbie H, Bullen C, Hartmann-Boyce J, et al. Electronic cigarettes for smoking cessation and reduction. Cochrane Database Syst Rev 2014; 12: CD010216.

Kalkhoran S, Glantz SA. E-cigarettes and smoking cessation - authors' reply. Lancet Respir Med 2016; 4: e26-e27.

Malas M, van der Tempel J, Schwartz R, et al. Electronic cigarettes for smoking cessation: a systematic review. Nicotine Tob Res 2016; 18: 1926-1936.

Beard E, West R, Michie S, et al. Association between electronic cigarette use and changes in quit attempts, success of quit attempts, use of smoking cessation pharmacotherapy, and use of stop smoking services in England: time series analysis of population trends. BMJ 2016; 354: i4645.

Tashkin DP, Rennard S, Hays JT, et al. Effects of varenicline on smoking cessation in patients with mild to moderate COPD: a randomized controlled trial. Chest 2011; 139: 591-599.

Tashkin D, Kanner R, Bailey W, et al. Smoking cessation in patients with chronic obstructive pulmonary disease: a double-blind, placebo-controlled, randomised trial. Lancet 2001; 357: 1571-1575.

The Tobacco Use and Dependence Clinical Practice Guideline Panels, and Consortium
practice guideline for treating tobacco use and dependence. JAMA 2000; 28: 3244-3254.

Glynn T, Manley M. How to help your patients stop smoking. A National Cancer Institute manual for physicians. NIH Publication No. 90-3064. Bethesda, National Cancer Institute, 1990.

Stead LF, Buitrago D, Preciado N, et al. Physician advice for smoking cessation. Cochrane Database Syst Rev 2013; 5: CD000165.

Stead LF, Koilpillai P, Fanshawe TR, et al. Combined pharmacotherapy and behavioural interventions for smoking cessation. Cochrane Database Syst Rev 2016; 3: CD008286.

Wongsurakiat $\mathrm{P}$, Maranetra $\mathrm{KN}$, Wasi $\mathrm{C}$, et al. Acute respiratory illness in patients with COPD and the effectiveness of influenza vaccination: a randomized controlled study. Chest 2004; 125: 2011-2020.

Poole PJ, Chacko E, Wood-Baker RW, et al. Influenza vaccine for patients with chronic obstructive pulmonary disease. Cochrane Database Syst Rev 2006; CD002733.

Wongsurakiat $\mathrm{P}$, Lertakyamanee J, Maranetra $\mathrm{KN}$, et al. Economic evaluation of influenza vaccination in Thai chronic obstructive pulmonary disease patients. J Med Assoc Thai 2003; 86: 497-508.

Nichol KL, Margolis KL, Wuorenma J, et al. The efficacy and cost effectiveness of vaccination against influenza among elderly persons living in the community. N Engl J Med 1994; 331: 778-784. 

of the Advisory Committee on Immunization Practices (ACIP), 2009. MMWR Recomm Rep 2009; 58: 1-52.

94 Huang CL, Nguyen PA, Kuo PL, et al. Influenza vaccination and reduction in risk of ischemic heart disease among chronic obstructive pulmonary elderly. Comput Methods Programs Biomed 2013; 111: 507-511.

95 Edwards KM, Dupont WD, Westrich MK, et al. A randomized controlled trial of cold-adapted and inactivated vaccines for the prevention of influenza A disease. J Infect Dis 1994; 169: 68-76.

96 Hak E, van Essen GA, Buskens E, et al. Is immunising all patients with chronic lung disease in the community against influenza cost effective? Evidence from a general practice based clinical prospective cohort study in Utrecht, The Netherlands. J Epidemiol Community Health 1998; 52: 120-125.

97 Burge PS, Calverley PM, Jones PW, et al. Randomised, double blind, placebo controlled study of fluticasone propionate in patients with moderate to severe chronic obstructive pulmonary disease: the ISOLDE trial. BMJ 2000; 320: 1297-1303.

98 Anthonisen NR, Connett JE, Kiley JP, et al. Effects of smoking intervention and the use of an inhaled anticholinergic bronchodilator on the rate of decline of FEV1. The Lung Health Study. JAMA 1994; 272: 1497-1505.

99 Pauwels RA, Lofdahl CG, Laitinen LA, et al. Long-term treatment with inhaled budesonide in persons with mild chronic obstructive pulmonary disease who continue smoking. European Respiratory Society Study on Chronic Obstructive Pulmonary Disease. N Engl J Med 1999; 340: 1948-1953.

100 Vestbo J, Sorensen T, Lange P, et al. Long-term effect of inhaled budesonide in mild and moderate chronic obstructive pulmonary disease: a randomised controlled trial. Lancet 1999; 353: 1819-1823.

101 Tashkin DP, Celli B, Senn S, et al. A 4-year trial of tiotropium in chronic obstructive pulmonary disease. N Engl J Med 2008; 359: 1543-1554.

102 O'Donnell DE, Fluge T, Gerken F, et al. Effects of tiotropium on lung hyperinflation, dyspnoea and exercise tolerance in COPD. Eur Respir J 2004; 23: 832-840.

103 O'Donnell DE, Sciurba F, Celli B, et al. Effect of fluticasone propionate/salmeterol on lung hyperinflation and exercise endurance in COPD. Chest 2006; 130: 647-656.

104 Appleton S, Jones T, Poole P, et al. Ipratropium bromide versus long-acting beta-2 agonists for stable chronic obstructive pulmonary disease. Cochrane Database Syst Rev 2006; 3: Cd006101.

105 Karner C, Chong J, Poole P. Tiotropium versus placebo for chronic obstructive pulmonary disease. Cochrane Database Syst Rev 2014; 7: CD009285.

106 Melani AS. Long-acting muscarinic antagonists. Expert Rev Clin Pharmacol 2015; 8: 479-501.

107 Kesten S, Casaburi R, Kukafka D, et al. Improvement in self-reported exercise participation with the combination of tiotropium and rehabilitative exercise training in COPD patients. Int J Chron Obstruct Pulmon Dis 2008; 3: $127-136$.

108 Casaburi R, Kukafka D, Cooper CB, et al. Improvement in exercise tolerance with the combination of tiotropium and pulmonary rehabilitation in patients with COPD. Chest 2005; 127: 809-817.

109 Vogelmeier C, Hederer B, Glaab T, et al. Tiotropium versus salmeterol for the prevention of exacerbations of COPD. N Engl J Med 2011; 364: 1093-1103.

110 Decramer ML, Chapman KR, Dahl R, et al. Once-daily indacaterol versus tiotropium for patients with severe chronic obstructive pulmonary disease (INVIGORATE): a randomised, blinded, parallel-group study. Lancet Respir Med 2013; 1: 524-533.

111 Anthonisen NR, Connett JE, Enright PL, et al. Hospitalizations and mortality in the Lung Health Study. Am J Respir Crit Care Med 2002; 166: 333-339.

112 Michele TM, Pinheiro S, Iyasu S. The safety of tiotropium - the FDA's conclusions. N Engl J Med 2010; 363: 1097-1099.

113 Wise RA, Anzueto A, Cotton D, et al. Tiotropium Respimat inhaler and the risk of death in COPD. $N$ Engl J Med 2013; 369: 1491-1501.

114 Ram FS, Jones PW, Castro AA, et al. Oral theophylline for chronic obstructive pulmonary disease. Cochrane Database Syst Rev 2002; 4: CD003902.

115 ZuWallack RL, Mahler DA, Reilly D, et al. Salmeterol plus theophylline combination therapy in the treatment of COPD. Chest 2001; 119: 1661-1670.

116 Zacarias EC, Castro AA, Cendon S. Effect of theophylline associated with short-acting or long-acting inhaled $\beta 2$-agonists in patients with stable chronic obstructive pulmonary disease: a systematic review. J Bras Pneumol 2007; 33: 152-160.

117 Cosio BG, Shafiek H, Iglesias A, et al. Oral low-dose theophylline on top of inhaled fluticasone-salmeterol does not reduce exacerbations in patients with severe COPD: a pilot clinical trial. Chest 2016; 150: 123-130.

118 Zhou Y, Wang X, Zeng X, et al. Positive benefits of theophylline in a randomized, double-blind, parallel-group, placebo-controlled study of low-dose, slow-release theophylline in the treatment of COPD for 1 year. Respirology 2006; 11: 603-610.

119 McKay SE, Howie CA, Thomson AH, et al. Value of theophylline treatment in patients handicapped by chronic obstructive lung disease. Thorax 1993; 48: 227-232.

120 Cazzola M, Molimard M. The scientific rationale for combining long-acting beta2-agonists and muscarinic antagonists in COPD. Pulm Pharmacol Ther 2010; 23: 257-267.

121 van der Molen T, Cazzola M. Beyond lung function in COPD management: effectiveness of LABA/LAMA combination therapy on patient-centred outcomes. Prim Care Respir J 2012; 21: 101-108.

122 Mahler DA, Decramer M, D’Urzo A, et al. Dual bronchodilation with QVA149 reduces patient-reported dyspnoea in COPD: the BLAZE study. Eur Respir J 2014; 43: 1599-1609.

123 Singh D, Ferguson GT, Bolitschek J, et al. Tiotropium + olodaterol shows clinically meaningful improvements in quality of life. Respir Med 2015; 109: 1312-1319.

124 Bateman ED, Chapman KR, Singh D, et al. Aclidinium bromide and formoterol fumarate as a fixed-dose combination in COPD: pooled analysis of symptoms and exacerbations from two six-month, multicentre, randomised studies (ACLIFORM and AUGMENT). Respir Res 2015; 16: 92.

125 Mahler DA, Kerwin E, Ayers T, et al. FLIGHT1 and FLIGHT2: efficacy and safety of QVA149 (indacaterol/ glycopyrrolate) versus its monocomponents and placebo in patients with chronic obstructive pulmonary disease. Am J Respir Crit Care Med 2015; 192: 1068-1079. 
Wedzicha JA, Decramer M, Ficker JH, et al. Analysis of chronic obstructive pulmonary disease exacerbations with the dual bronchodilator QVA149 compared with glycopyrronium and tiotropium (SPARK): a randomised, double-blind, parallel-group study. Lancet Respir Med 2013; 1: 199-209.

127 Wedzicha JA, Banerji D, Chapman KR, et al. Indacaterol-glycopyrronium versus salmeterol-fluticasone for COPD. N Engl J Med 2016; 374: 2222-2234.

128 Nannini LJ, Lasserson TJ, Poole P. Combined corticosteroid and long-acting $\beta_{2}$-agonist in one inhaler versus long-acting $\beta_{2}$-agonists for chronic obstructive pulmonary disease. Cochrane Database Syst Rev 2012; 9: CD006829.

129 Nannini LJ, Poole P, Milan SJ, et al. Combined corticosteroid and long-acting $\beta_{2}$-agonist in one inhaler versus inhaled corticosteroids alone for chronic obstructive pulmonary disease. Cochrane Database Syst Rev 2013; 8: CD006826.

130 Calverley PM, Anderson JA, Celli B, et al. Salmeterol and fluticasone propionate and survival in chronic obstructive pulmonary disease. N Engl J Med 2007; 356: 775-789.

131 Vestbo J, Anderson JA, Brook RD, et al. Fluticasone furoate and vilanterol and survival in chronic obstructive pulmonary disease with heightened cardiovascular risk (SUMMIT): a double-blind randomised controlled trial. Lancet 2016; 387: 1817-1826.

132 Yang IA, Clarke MS, Sim EH, et al. Inhaled corticosteroids for stable chronic obstructive pulmonary disease. Cochrane Database Syst Rev 2012; 7: CD002991.

133 Crim C, Dransfield MT, Bourbeau J, et al. Pneumonia risk with inhaled fluticasone furoate and vilanterol compared with vilanterol alone in patients with COPD. Ann Am Thorac Soc 2015; 12: 27-34.

134 Johnell O, Pauwels R, Lofdahl CG, et al. Bone mineral density in patients with chronic obstructive pulmonary disease treated with budesonide Turbuhaler. Eur Respir J 2002; 19: 1058-1063.

135 Ferguson GT, Calverley PM, Anderson JA, et al. Prevalence and progression of osteoporosis in patients with COPD: results from the TOwards a Revolution in COPD Health study. Chest 2009; 136: 1456-1465.

136 Dransfield MT, Bourbeau J, Jones PW, et al. Once-daily inhaled fluticasone furoate and vilanterol versus vilanterol only for prevention of exacerbations of COPD: two replicate double-blind, parallel-group, randomised controlled trials. Lancet Respir Med 2013; 1: 210-223.

137 Loke YK, Cavallazzi R, Singh S. Risk of fractures with inhaled corticosteroids in COPD: systematic review and meta-analysis of randomised controlled trials and observational studies. Thorax 2011; 66: 699-708.

138 Suissa S, Kezouh A, Ernst P. Inhaled corticosteroids and the risks of diabetes onset and progression. Am J Med 2010; 123: 1001-1006.

139 Wang JJ, Rochtchina E, Tan AG, et al. Use of inhaled and oral corticosteroids and the long-term risk of cataract. Ophthalmology 2009; 116: 652-657.

140 Andrejak C, Nielsen R, Thomsen VO, et al. Chronic respiratory disease, inhaled corticosteroids and risk of non-tuberculous mycobacteriosis. Thorax 2013; 68: 256-262.

141 Dong YH, Chang $\mathrm{CH}$, Lin Wu FL, et al. Use of inhaled corticosteroids in patients with COPD and the risk of TB and influenza: a systematic review and meta-analysis of randomized controlled trials. Chest 2014; 145: 1286-1297.

142 Lee $\mathrm{CH}$, Kim K, Hyun MK, et al. Use of inhaled corticosteroids and the risk of tuberculosis. Thorax 2013; 68: $1105-1113$.

143 Nadeem NJ, Taylor SJ, Eldridge SM. Withdrawal of inhaled corticosteroids in individuals with COPD - a systematic review and comment on trial methodology. Respir Res 2011; 12: 107.

144 van der Valk P, Monninkhof E, van der Palen J, et al. Effect of discontinuation of inhaled corticosteroids in patients with chronic obstructive pulmonary disease: the COPE study. Am J Respir Crit Care Med 2002; 166: $1358-1363$

145 Wouters EF, Postma DS, Fokkens B, et al. Withdrawal of fluticasone propionate from combined salmeterol/ fluticasone treatment in patients with COPD causes immediate and sustained disease deterioration: a randomised controlled trial. Thorax 2005; 60: 480-487.

146 Kunz LI, Postma DS, Klooster K, et al. Relapse in FEVı decline after steroid withdrawal in COPD. Chest 2015; 148: $389-396$

147 Magnussen H, Disse B, Rodriguez-Roisin R, et al. Withdrawal of inhaled glucocorticoids and exacerbations of COPD. N Engl J Med 2014; 371: 1285-1294.

148 Welte T, Miravitlles M, Hernandez P, et al. Efficacy and tolerability of budesonide/formoterol added to tiotropium in patients with chronic obstructive pulmonary disease. Am J Respir Crit Care Med 2009; 180: 741-750.

149 Singh D, Brooks J, Hagan G, et al. Superiority of "triple" therapy with salmeterol/fluticasone propionate and tiotropium bromide versus individual components in moderate to severe COPD. Thorax 2008; 63: 592-598.

150 Jung KS, Park HY, Park SY, et al. Comparison of tiotropium plus fluticasone propionate/salmeterol with tiotropium in COPD: a randomized controlled study. Respir Med 2012; 106: 382-389.

151 Hanania NA, Crater GD, Morris AN, et al. Benefits of adding fluticasone propionate/salmeterol to tiotropium in moderate to severe COPD. Respir Med 2012; 106: 91-101.

152 Frith PA, Thompson PJ, Ratnavadivel R, et al. Glycopyrronium once-daily significantly improves lung function and health status when combined with salmeterol/fluticasone in patients with COPD: the GLISTEN study, a randomised controlled trial. Thorax 2015; 70: 519-527.

153 Siler TM, Kerwin E, Singletary K, et al. Efficacy and safety of umeclidinium added to fluticasone propionate/ salmeterol in patients with COPD: results of two randomized, double-blind studies. COPD 2016; 13: 1-10.

154 Singh D, Papi A, Corradi M, et al. Single inhaler triple therapy versus inhaled corticosteroid plus long-acting 32 -agonist therapy for chronic obstructive pulmonary disease (TRILOGY): a double-blind, parallel group, randomised controlled trial. Lancet 2016; 388: 963-973.

155 Aaron SD, Vandemheen KL, Fergusson D, et al. Tiotropium in combination with placebo, salmeterol, or fluticasone-salmeterol for treatment of chronic obstructive pulmonary disease: a randomized trial. Ann Intern Med 2007; 146: 545-555.

156 Calverley PM, Rabe KF, Goehring UM, et al. Roflumilast in symptomatic chronic obstructive pulmonary disease: two randomised clinical trials. Lancet 2009; 374: 685-694.

157 Chong J, Leung B, Poole P. Phosphodiesterase 4 inhibitors for chronic obstructive pulmonary disease. Cochrane Database Syst Rev 2013; 11: CD002309. 
158 Seemungal TA, Wilkinson TM, Hurst JR, et al. Long-term erythromycin therapy is associated with decreased chronic obstructive pulmonary disease exacerbations. Am J Respir Crit Care Med 2008; 178: 1139-1147.

Uzun S, Djamin RS, Kluytmans JA, et al. Azithromycin maintenance treatment in patients with frequent exacerbations of chronic obstructive pulmonary disease (COLUMBUS): a randomised, double-blind, placebo-controlled trial. Lancet Respir Med 2014; 2: 361-368.

160 Albert RK, Connett J, Bailey WC, et al. Azithromycin for prevention of exacerbations of COPD. N Engl J Med 2011; 365: 689-698.

161 Sethi S, Jones PW, Theron MS, et al. Pulsed moxifloxacin for the prevention of exacerbations of chronic obstructive pulmonary disease: a randomized controlled trial. Respir Res 2010; 11: 10 .

162 Cazzola M, Calzetta L, Page C, et al. Influence of $N$-acetylcysteine on chronic bronchitis or COPD exacerbations: a meta-analysis. Eur Respir Rev 2015; 24: 451-461.

163 Poole P, Chong J, Cates CJ. Mucolytic agents versus placebo for chronic bronchitis or chronic obstructive pulmonary disease. Cochrane Database Syst Rev 2015; 7: CD001287.

164 Collet JP, Shapiro P, Ernst P, et al. Effects of an immunostimulating agent on acute exacerbations and hospitalizations in patients with chronic obstructive pulmonary disease. The PARI-IS Study Steering Committee and Research Group. Prevention of Acute Respiratory Infection by an Immunostimulant. Am J Respir Crit Care Med 1997; 156: 1719-1724.

165 Li J, Zheng JP, Yuan JP, et al. Protective effect of a bacterial extract against acute exacerbation in patients with chronic bronchitis accompanied by chronic obstructive pulmonary disease. Chin Med J 2004; 117: 828-834

166 Lee JH, Kim HJ, Kim YH. The effectiveness of anti-leukotriene agents in patients with COPD: a systemic review and meta-analysis. Lung 2015; 193: 477-486.

167 Rennard SI, Fogarty C, Kelsen S, et al. The safety and efficacy of infliximab in moderate to severe chronic obstructive pulmonary disease. Am J Respir Crit Care Med 2007; 175: 926-934.

168 Criner GJ, Connett JE, Aaron SD, et al. Simvastatin for the prevention of exacerbations in moderate-to-severe COPD. N Engl J Med 2014; 370: 2201-2210.

169 Ingebrigtsen TS, Marott JL, Nordestgaard BG, et al. Statin use and exacerbations in individuals with chronic obstructive pulmonary disease. Thorax 2015; 70: 33-40.

170 Lehouck A, Mathieu C, Carremans C, et al. High doses of vitamin D to reduce exacerbations in chronic obstructive pulmonary disease: a randomized trial. Ann Intern Med 2012; 156: 105-114.

171 Melani AS, Bonavia M, Cilenti V, et al. Inhaler mishandling remains common in real life and is associated with reduced disease control. Respir Med 2011; 105: 930-938

172 Rootmensen GN, van Keimpema AR, Jansen HM, et al. Predictors of incorrect inhalation technique in patients with asthma or COPD: a study using a validated videotaped scoring method. J Aerosol Med Pulm Drug Deliv 2010; 23: 323-328.

173 Dantic DE. A critical review of the effectiveness of "teach-back" technique in teaching COPD patients self-management using respiratory inhalers. Health Educ J 2014; 73: 41-50.

174 Chapman KR, Stockley RA, Dawkins C, et al. Augmentation therapy for $\alpha 1$ antitrypsin deficiency: a meta-analysis. COPD 2009; 6: 177-184.

175 Chapman KR, Burdon JG, Piitulainen E, et al. Intravenous augmentation treatment and lung density in severe $\alpha 1$ antitrypsin deficiency (RAPID): a randomised, double-blind, placebo-controlled trial. Lancet 2015; 386: 360-368.

176 Dirksen A, Dijkman JH, Madsen F, et al. A randomized clinical trial of $\alpha_{1}$-antitrypsin augmentation therapy. Am J Respir Crit Care Med 1999; 160: 1468-1472.

177 Dirksen A, Piitulainen E, Parr DG, et al. Exploring the role of CT densitometry: a randomised study of augmentation therapy in alpha1-antitrypsin deficiency. Eur Respir J 2009; 33: 1345-1353.

178 Schildmann EK, Remi C, Bausewein C. Levodropropizine in the management of cough associated with cancer or nonmalignant chronic disease - a systematic review. J Pain Palliat Care Pharmacother 2011; 25: 209-218.

179 Barbera JA, Roger N, Roca J, et al. Worsening of pulmonary gas exchange with nitric oxide inhalation in chronic obstructive pulmonary disease. Lancet 1996; 347: 436-440.

180 Blanco I, Santos S, Gea J, et al. Sildenafil to improve respiratory rehabilitation outcomes in COPD: a controlled trial. Eur Respir J 2013; 42: 982-992.

181 Goudie AR, Lipworth BJ, Hopkinson PJ, et al. Tadalafil in patients with chronic obstructive pulmonary disease: a randomised, double-blind, parallel-group, placebo-controlled trial. Lancet Respir Med 2014; 2: 293-300.

182 Spruit MA, Singh SJ, Garvey C, et al. An official American Thoracic Society/European Respiratory Society statement: key concepts and advances in pulmonary rehabilitation. Am J Respir Crit Care Med 2013; 188: e13-e64.

183 Puhan MA, Gimeno-Santos E, Scharplatz M, et al. Pulmonary rehabilitation following exacerbations of chronic obstructive pulmonary disease. Cochrane Database Syst Rev 2011; 10: CD005305.

184 Greening NJ, Williams JE, Hussain SF, et al. An early rehabilitation intervention to enhance recovery during hospital admission for an exacerbation of chronic respiratory disease: randomised controlled trial. BMJ 2014; 349: g4315.

185 Vogiatzis I, Rochester CL, Spruit MA, et al. Increasing implementation and delivery of pulmonary rehabilitation: key messages from the new ATS/ERS policy statement. Eur Respir J 2016; 47: 1336-1341.

186 Zwerink M, Brusse-Keizer M, van der Valk PD, et al. Self management for patients with chronic obstructive pulmonary disease. Cochrane Database Syst Rev 2014; 3: CD002990.

187 Fan VS, Gaziano JM, Lew R, et al. A comprehensive care management program to prevent chronic obstructive pulmonary disease hospitalizations: a randomized, controlled trial. Ann Intern Med 2012; 156: 673-683.

188 Peytremann-Bridevaux I, Taffe P, Burnand B, et al. Mortality of patients with COPD participating in chronic disease management programmes: a happy end? Thorax 2014; 69: 865-866.

189 Kruis AL, Smidt N, Assendelft WJ, et al. Integrated disease management interventions for patients with chronic obstructive pulmonary disease. Cochrane Database Syst Rev 2013; 10: CD009437.

190 Kruis AL, Boland MR, Assendelft WJ, et al. Effectiveness of integrated disease management for primary care chronic obstructive pulmonary disease patients: results of cluster randomised trial. BMJ 2014; 349: g5392.

191 Cartwright M, Hirani SP, Rixon L, et al. Effect of telehealth on quality of life and psychological outcomes over 12 months (Whole Systems Demonstrator telehealth questionnaire study): nested study of patient reported outcomes in a pragmatic, cluster randomised controlled trial. BMJ 2013; 346: f653. 
192 American Academy of Hospice and Palliative Medicine Center to Advance Palliative Care Hospice, Palliative Nurses Association Last Acts Partnership National Hospice and Palliative Care Organization. National Consensus Project for Quality Palliative Care: Clinical Practice Guidelines for quality palliative care, executive summary. J Palliat Med 2004; 7: 611-627.

193 Halpin DMG, Seamark DA, Seamark CJ. Palliative and end-of-life care for patients with respiratory diseases. In: Bellia V, Antonelli Incalzi R, eds. Respiratory Diseases in the Elderly (ERS Monograph). Sheffield, European Respiratory Society, 2009; pp. 327-353.

194 Weber C, Stirnemann J, Herrmann FR, et al. Can early introduction of specialized palliative care limit intensive care, emergency and hospital admissions in patients with severe and very severe COPD? a randomized study. BMC Palliat Care 2014; 13: 47.

195 Ek K, Andershed B, Sahlberg-Blom E, et al. "The unpredictable death" - the last year of life for patients with advanced COPD: relatives' stories. Palliat Support Care 2015; 13: 1213-1222.

196 Cranston JM, Crockett AJ, Moss JR, et al. Domiciliary oxygen for chronic obstructive pulmonary disease. Cochrane Database Syst Rev 2005; 4 CD001744.

197 Long-term Oxygen Treatment Trial Research Group. A randomized trial of long-term oxygen for COPD with moderate desaturation. N Engl J Med 2016; 375: 1617.

198 Galli JA, Krahnke JS, James Mamary A, et al. Home non-invasive ventilation use following acute hypercapnic respiratory failure in COPD. Respir Med 2014; 108: 722-728.

199 Coughlin S, Liang WE, Parthasarathy S. Retrospective assessment of home ventilation to reduce rehospitalization in chronic obstructive pulmonary disease. J Clin Sleep Med 2015; 11: 663-670.

200 Clini E, Sturani C, Rossi A, et al. The Italian multicentre study on noninvasive ventilation in chronic obstructive pulmonary disease patients. Eur Respir J 2002; 20: 529-538.

201 Kohnlein T, Windisch W, Kohler D, et al. Non-invasive positive pressure ventilation for the treatment of severe stable chronic obstructive pulmonary disease: a prospective, multicentre, randomised, controlled clinical trial. Lancet Respir Med 2014; 2: 698-705.

202 Struik FM, Sprooten RT, Kerstjens HA, et al. Nocturnal non-invasive ventilation in COPD patients with prolonged hypercapnia after ventilatory support for acute respiratory failure: a randomised, controlled, parallel-group study. Thorax 2014; 69: 826-834.

203 Casanova C, Celli BR, Tost L, et al. Long-term controlled trial of nocturnal nasal positive pressure ventilation in patients with severe COPD. Chest 2000; 118: 1582-1590.

204 Marin JM, Soriano JB, Carrizo SJ, et al. Outcomes in patients with chronic obstructive pulmonary disease and obstructive sleep apnea: the overlap syndrome. Am J Respir Crit Care Med 2010; 182: 325-331.

205 Fishman A, Martinez F, Naunheim K, et al. A randomized trial comparing lung-volume-reduction surgery with medical therapy for severe emphysema. N Engl J Med 2003; 348: 2059-2073.

206 National Emphysema Treatment Trial Research Group. Patients at high risk of death after lung-volume-reduction surgery. N Engl J Med 2001; 345: 1075-1083.

207 Marchetti N, Criner GJ. Surgical approaches to treating emphysema: lung volume reduction surgery, bullectomy, and lung transplantation. Semin Respir Crit Care Med 2015; 36: 592-608.

208 Christie JD, Edwards LB, Kucheryavaya AY, et al. The Registry of the International Society for Heart and Lung Transplantation: 29th adult lung and heart-lung transplant report - 2012. J Heart Lung Transplant 2012; 31: $1073-1086$

209 Stavem K, Bjortuft O, Borgan O, et al. Lung transplantation in patients with chronic obstructive pulmonary disease in a national cohort is without obvious survival benefit. J Heart Lung Transplant 2006; 25: 75-84.

210 Thabut G, Christie JD, Ravaud P, et al. Survival after bilateral versus single lung transplantation for patients with chronic obstructive pulmonary disease: a retrospective analysis of registry data. Lancet 2008; 371: 744-751.

211 Criner GJ, Cordova F, Sternberg AL, et al. The National Emphysema Treatment Trial (NETT) Part II: Lessons learned about lung volume reduction surgery. Am J Respir Crit Care Med 2011; 184: 881-893.

212 Shah PL, Slebos DJ, Cardoso PF, et al. Bronchoscopic lung-volume reduction with Exhale airway stents for emphysema (EASE trial): randomised, sham-controlled, multicentre trial. Lancet 2011; 378: 997-1005.

213 Come CE, Kramer MR, Dransfield MT, et al. A randomised trial of lung sealant versus medical therapy for advanced emphysema. Eur Respir J 2015; 46: 651-662.

214 Sciurba FC, Ernst A, Herth FJ, et al. A randomized study of endobronchial valves for advanced emphysema. N Engl J Med 2010; 363: 1233-1244.

215 Davey C, Zoumot Z, Jordan S, et al. Bronchoscopic lung volume reduction with endobronchial valves for patients with heterogeneous emphysema and intact interlobar fissures (the BeLieVeR-HIFi trial): study design and rationale. Thorax 2015; 70: 288-290.

216 Klooster K, ten Hacken NH, Hartman JE, et al. Endobronchial valves for emphysema without interlobar collateral ventilation. N Engl J Med 2015; 373: 2325-2335.

217 Deslee G, Mal H, Dutau H, et al. Lung volume reduction coil treatment $v s$ usual care in patients with severe emphysema: the REVOLENS randomized clinical trial. JAMA 2016; 315: 175-184.

218 Sciurba FC, Criner GJ, Strange C, et al. Effect of endobronchial coils vs usual care on exercise tolerance in patients with severe emphysema: the RENEW randomized clinical trial. JAMA 2016; 315: 2178-2189.

219 Barr RG, Bourbeau J, Camargo CA, et al. Inhaled tiotropium for stable chronic obstructive pulmonary disease. Cochrane Database Syst Rev 2005; 2 CD002876.

220 Karner $C$, Cates CJ. Long-acting $\beta_{2}$-agonist in addition to tiotropium versus either tiotropium or long-acting $\beta_{2}$-agonist alone for chronic obstructive pulmonary disease. Cochrane Database Syst Rev 2012; 4: CD008989.

221 Martinez FJ, Calverley PM, Goehring UM, et al. Effect of roflumilast on exacerbations in patients with severe chronic obstructive pulmonary disease uncontrolled by combination therapy (REACT): a multicentre randomised controlled trial. Lancet 2015; 385: 857-866.

222 Martinez FJ, Rabe KF, Sethi S, et al. Effect of roflumilast and inhaled corticosteroid/long-acting $\beta 2$-agonist on chronic obstructive pulmonary disease exacerbations (RE(2)SPOND). A randomized clinical trial. Am J Respir Crit Care Med 2016; 194: 559-567.

223 Garvey C, Bayles MP, Hamm LF, et al. Pulmonary rehabilitation exercise prescription in chronic obstructive pulmonary disease: review of selected guidelines: an official statement from the american association of cardiovascular and pulmonary rehabilitation. J Cardiopulm Rehabil Prev 2016; 36: 75-83. 
Ortega F, Toral J, Cejudo P, et al. Comparison of effects of strength and endurance training in patients with chronic obstructive pulmonary disease. Am J Respir Crit Care Med 2002; 166: 669-674.

Bernard S, Whittom F, Leblanc P, et al. Aerobic and strength training in patients with chronic obstructive pulmonary disease. Am J Respir Crit Care Med 1999; 159: 896-901.

Velloso M, do Nascimento NH, Gazzotti MR, et al. Evaluation of effects of shoulder girdle training on strength and performance of activities of daily living in patients with chronic obstructive pulmonary disease. Int J Chron Obstruct Pulmon Dis 2013; 8: 187-192.

Au DH, Udris EM, Engelberg RA, et al. A randomized trial to improve communication about end-of-life care among patients with COPD. Chest 2012; 141: 726-735.

Tomczyk S, Bennett NM, Stoecker C, et al. Use of 13-valent pneumococcal conjugate vaccine and 23-valent pneumococcal polysaccharide vaccine among adults aged $\geqslant 65$ years: recommendations of the Advisory Committee on Immunization Practices (ACIP). MMWR Morb Mortal Wkly Rep 2014; 63: 822-825.

Struik FM, Lacasse Y, Goldstein RS, et al. Nocturnal noninvasive positive pressure ventilation in stable COPD: a systematic review and individual patient data meta-analysis. Respir Med 2014; 108: 329-337.

Tiong LU, Davies R, Gibson PG, et al. Lung volume reduction surgery for diffuse emphysema. Cochrane Database Syst Rev 2006; 4: CD001001.

Weill D, Benden C, Corris PA, et al. A consensus document for the selection of lung transplant candidates: 2014 - an update from the Pulmonary Transplantation Council of the International Society for Heart and Lung Transplantation. J Heart Lung Transplant 2015; 34: 1-15.

ISHLT. Slide Sets - Overall Lung Transplantation Statistics. www.ishlt.org/downloadables/slides/2015/lung_adult. pptx Date last accessed: September 18, 2016.

Wedzicha JA, Seemungal TA. COPD exacerbations: defining their cause and prevention. Lancet 2007; 370: 786-796.

Seemungal TA, Donaldson GC, Paul EA, et al. Effect of exacerbation on quality of life in patients with chronic obstructive pulmonary disease. Am J Respir Crit Care Med 1998; 157: 1418-1422.

Anthonisen NR, Manfreda J, Warren CP, et al. Antibiotic therapy in exacerbations of chronic obstructive pulmonary disease. Ann Intern Med 1987; 106: 196-204.

Woodhead M, Blasi F, Ewig S, et al. Guidelines for the management of adult lower respiratory tract infections. Eur Respir J 2005; 26: 1138-1180.

White AJ, Gompertz S, Stockley RA. Chronic obstructive pulmonary disease. 6: The aetiology of exacerbations of chronic obstructive pulmonary disease. Thorax 2003; 58: 73-80.

Papi A, Bellettato CM, Braccioni F, et al. Infections and airway inflammation in chronic obstructive pulmonary disease severe exacerbations. Am J Respir Crit Care Med 2006; 173: 1114-1121.

Bafadhel M, McKenna S, Terry S, et al. Blood eosinophils to direct corticosteroid treatment of exacerbations of chronic obstructive pulmonary disease: a randomized placebo-controlled trial. Am J Respir Crit Care Med 2012; 186: 48-55.

Seemungal TA, Donaldson GC, Bhowmik A, et al. Time course and recovery of exacerbations in patients with chronic obstructive pulmonary disease. Am J Respir Crit Care Med 2000; 161: 1608-1613.

Hurst JR, Donaldson GC, Quint JK, et al. Temporal clustering of exacerbations in chronic obstructive pulmonary disease. Am J Respir Crit Care Med 2009; 179: 369-374.

Wells JM, Washko GR, Han MK, et al. Pulmonary arterial enlargement and acute exacerbations of COPD. N Engl J Med 2012; 367: 913-921.

Han MK, Kazerooni EA, Lynch DA, et al. Chronic obstructive pulmonary disease exacerbations in the COPDGene study: associated radiologic phenotypes. Radiology 2011; 261: 274-282.

Kim V, Han MK, Vance GB, et al. The chronic bronchitic phenotype of COPD: an analysis of the COPDGene Study. Chest 2011; 140: 626-633.

Burgel PR, Nesme-Meyer P, Chanez P, et al. Cough and sputum production are associated with frequent exacerbations and hospitalizations in COPD subjects. Chest 2009; 135: 975-982.

Martinez FJ, Han MK, Flaherty K, et al. Role of infection and antimicrobial therapy in acute exacerbations of chronic obstructive pulmonary disease. Expert Rev Anti Infect Ther 2006; 4: 101-124.

Celli BR, Thomas NE, Anderson JA, et al. Effect of pharmacotherapy on rate of decline of lung function in chronic obstructive pulmonary disease: results from the TORCH study. Am J Respir Crit Care Med 2008; 178: 332-338.

2008; 31: 742-750.

Hoogendoorn M, Hoogenveen RT, Rutten-van Molken MP, et al. Case fatality of COPD exacerbations: a meta-analysis and statistical modelling approach. Eur Respir J 2011; 37: 508-515.

Piquet J, Chavaillon JM, David P, et al. High-risk patients following hospitalisation for an acute exacerbation of COPD. Eur Respir J 2013; 42: 946-955.

Singanayagam A, Schembri S, Chalmers JD. Predictors of mortality in hospitalized adults with acute exacerbation of chronic obstructive pulmonary disease. Ann Am Thorac Soc 2013; 10: 81-89.

Garcia-Aymerich J, Serra Pons I, Mannino DM, et al. Lung function impairment, COPD hospitalisations and subsequent mortality. Thorax 2011; 66: 585-590.

National Institute for Health and Care Excellence. Chronic obstructive pulmonary disease in over 16s: diagnosis and management. 2010. www.nice.org.uk/guidance/CG101 Date last accessed: February 8, 2017.

Celli BR, MacNee W, ATS ERS Task Force. Standards for the diagnosis and treatment of patients with COPD a summary of the ATS/ERS position paper. Eur Respir J 2004; 23: 932-946.

Arch Intern Med 1997; 157: 1736-1744.

Barr RG, Rowe BH, Camargo CA Jr. Methylxanthines for exacerbations of chronic obstructive pulmonary disease: meta-analysis of randomised trials. BMJ 2003; 327: 643.

Duffy $\mathrm{N}$, Walker P, Diamantea F, et al. Intravenous aminophylline in patients admitted to hospital with non-acidotic exacerbations of chronic obstructive pulmonary disease: a prospective randomised controlled trial. Thorax 2005; 60: 713-717.

258 Davies L, Angus RM, Calverley PM. Oral corticosteroids in patients admitted to hospital with exacerbations of chronic obstructive pulmonary disease: a prospective randomised controlled trial. Lancet 1999; 354: 456-460. 
Maltais F, Ostinelli J, Bourbeau J, et al. Comparison of nebulized budesonide and oral prednisolone with placebo in the treatment of acute exacerbations of chronic obstructive pulmonary disease: a randomized controlled trial. Am J Respir Crit Care Med 2002; 165: 698-703.

260 Niewoehner DE, Erbland ML, Deupree RH, et al. Effect of systemic glucocorticoids on exacerbations of chronic obstructive pulmonary disease. Department of Veterans Affairs Cooperative Study Group. N Engl J Med 1999; 340: 1941-1947.

261 Thompson WH, Nielson CP, Carvalho P, et al. Controlled trial of oral prednisone in outpatients with acute COPD exacerbation. Am J Respir Crit Care Med 1996; 154: 407-412.

262 Alia I, de la Cal MA, Esteban A, et al. Efficacy of corticosteroid therapy in patients with an acute exacerbation of chronic obstructive pulmonary disease receiving ventilatory support. Arch Intern Med 2011; 171: 1939-1946.

263 Aaron SD, Vandemheen KL, Hebert P, et al. Outpatient oral prednisone after emergency treatment of chronic obstructive pulmonary disease. N Engl J Med 2003; 348: 2618-2625.

264 Leuppi JD, Schuetz P, Bingisser R, et al. Short-term vs conventional glucocorticoid therapy in acute exacerbations of chronic obstructive pulmonary disease: the REDUCE randomized clinical trial. JAMA 2013; 309: 2223-2231.

265 de Jong YP, Uil SM, Grotjohan HP, et al. Oral or IV prednisolone in the treatment of COPD exacerbations: a randomized, controlled, double-blind study. Chest 2007; 132: 1741-1747.

266 Bafadhel M, McKenna S, Terry S, et al. Acute exacerbations of chronic obstructive pulmonary disease: identification of biologic clusters and their biomarkers. Am J Respir Crit Care Med 2011; 184: 662-671.

267 Vollenweider DJ, Jarrett H, Steurer-Stey CA, et al. Antibiotics for exacerbations of chronic obstructive pulmonary disease. Cochrane Database Syst Rev 2012; 12: CD010257.

268 Miravitlles M, Kruesmann F, Haverstock D, et al. Sputum colour and bacteria in chronic bronchitis exacerbations: a pooled analysis. Eur Respir J 2012; 39: 1354-1360.

269 Stockley RA, O'Brien C, Pye A, et al. Relationship of sputum color to nature and outpatient management of acute exacerbations of COPD. Chest 2000; 117: 1638-1645.

270 Ram FS, Rodriguez-Roisin R, Granados-Navarrete A, et al. Antibiotics for exacerbations of chronic obstructive pulmonary disease. Cochrane Database Syst Rev 2006; 2: CD004403.

271 Schuetz P, Christ-Crain M, Thomann R, et al. Effect of procalcitonin-based guidelines vs standard guidelines on antibiotic use in lower respiratory tract infections: the ProHOSP randomized controlled trial. JAMA 2009; 302: 1059-1066.

272 Schuetz P, Muller B, Christ-Crain M, et al. Procalcitonin to initiate or discontinue antibiotics in acute respiratory tract infections. Cochrane Database Syst Rev 2012; 9: CD007498.

273 Nouira S, Marghli S, Belghith M, et al. Once daily oral ofloxacin in chronic obstructive pulmonary disease exacerbation requiring mechanical ventilation: a randomised placebo- controlled trial. Lancet 2001; 358: 2020-2025.

274 Masterton RG, Burley CJ. Randomized, double-blind study comparing 5- and 7-day regimens of oral levofloxacin in patients with acute exacerbation of chronic bronchitis. Int J Antimicrob Agents 2001; 18: 503-512.

275 Adams SG, Melo J, Luther M. Antibiotics are associated with lower relapse rates in outpatients with acute exacerbations of chronic obstructive pulmonary disease. Chest 2000; 117: 1345-1352.

276 Miravitlles M, Espinosa C, Fernandez-Laso E, et al. Relationship between bacterial flora in sputum and functional impairment in patients with acute exacerbations of COPD. Study Group of Bacterial Infection in COPD. Chest 1999; 116: 40-46.

277 Soler N, Torres A, Ewig S, et al. Bronchial microbial patterns in severe exacerbations of chronic obstructive pulmonary disease (COPD) requiring mechanical ventilation. Am J Respir Crit Care Med 1998; 157: 1498-1505.

278 Austin MA, Wills KE, Blizzard L, et al. Effect of high flow oxygen on mortality in chronic obstructive pulmonary disease patients in prehospital setting: randomised controlled trial. BMJ 2010; 341: c5462.

279 Brochard L, Mancebo J, Wysocki M, et al. Noninvasive ventilation for acute exacerbations of chronic obstructive pulmonary disease. N Engl J Med 1995; 333: 817-822.

280 Lightowler JV, Wedzicha JA, Elliott MW, et al. Non-invasive positive pressure ventilation to treat respiratory failure resulting from exacerbations of chronic obstructive pulmonary disease: Cochrane systematic review and meta-analysis. BMJ 2003; 326: 185.

281 Meyer TJ, Hill NS. Noninvasive positive pressure ventilation to treat respiratory failure. Ann Intern Med 1994; 120: $760-770$.

282 Chandra D, Stamm JA, Taylor B, et al. Outcomes of noninvasive ventilation for acute exacerbations of chronic obstructive pulmonary disease in the United States, 1998-2008. Am J Respir Crit Care Med 2012; 185: 152-159.

283 Consensus development conference committee. Clinical indications for noninvasive positive pressure ventilation in chronic respiratory failure due to restrictive lung disease, COPD, and nocturnal hypoventilation - a consensus conference report. Chest 1999; 116: 521-534

284 Bott J, Carroll MP, Conway JH, et al. Randomised controlled trial of nasal ventilation in acute ventilatory failure due to chronic obstructive airways disease. Lancet 1993; 341: 1555-1557.

285 Kramer N, Meyer TJ, Meharg J, et al. Randomized, prospective trial of noninvasive positive pressure ventilation in acute respiratory failure. Am J Respir Crit Care Med 1995; 151: 1799-1806.

286 Plant PK, Owen JL, Elliott MW. Early use of non-invasive ventilation for acute exacerbations of chronic obstructive pulmonary disease on general respiratory wards: a multicentre randomised controlled trial. Lancet 2000; 355: 1931-1935.

287 Conti G, Antonelli M, Navalesi P, et al. Noninvasive vs. conventional mechanical ventilation in patients with chronic obstructive pulmonary disease after failure of medical treatment in the ward: a randomized trial. Intensive Care Med 2002; 28: 1701-1707.

288 Jennings JH, Thavarajah K, Mendez MP, et al. Predischarge bundle for patients with acute exacerbations of COPD to reduce readmissions and ED visits: a randomized controlled trial. Chest 2015; 147: 1227-1234.

289 Singh G, Zhang W, Kuo YF, et al. Association of psychological disorders with 30-day readmission rates in patients with COPD. Chest 2016; 149: 905-915.

290 Ringbaek T, Green A, Laursen LC, et al. Effect of tele health care on exacerbations and hospital admissions in patients with chronic obstructive pulmonary disease: a randomized clinical trial. Int J Chron Obstruct Pulmon Dis 2015; 10: 1801-1808. 
Hartl S, Lopez-Campos JL, Pozo-Rodriguez F, et al. Risk of death and readmission of hospital-admitted COPD exacerbations: European COPD Audit. Eur Respir J 2016; 47: 113-121.

Jordan RE, Majothi S, Heneghan NR, et al. Supported self-management for patients with moderate to severe chronic obstructive pulmonary disease (COPD): an evidence synthesis and economic analysis. Health Technol Assess 2015; 19: 1-516.

Gavish R, Levy A, Dekel OK, et al. The association between hospital readmission and pulmonologist follow-up visits in patients with COPD. Chest 2015; 148: 375-381.

Oga T, Tsukino M, Hajiro T, et al. Predictive properties of different multidimensional staging systems in patients with chronic obstructive pulmonary disease. Int J Chron Obstruct Pulmon Dis 2011; 6: 521-526.

Martinez-Garcia MA, de la Rosa Carrillo D, Soler-Cataluna JJ, et al. Prognostic value of bronchiectasis in patients with moderate-to-severe chronic obstructive pulmonary disease. Am J Respir Crit Care Med 2013; 187: 823-831. Barnes PJ, Celli BR. Systemic manifestations and comorbidities of COPD. Eur Respir J 2009; 33: 1165-1185.

Mannino DM, Thorn D, Swensen A, et al. Prevalence and outcomes of diabetes, hypertension and cardiovascular disease in COPD. Eur Respir J 2008; 32: 962-969.

Sin DD, Anthonisen NR, Soriano JB, et al. Mortality in COPD: Role of comorbidities. Eur Respir J 2006; 28 : $1245-1257$.

Iversen KK, Kjaergaard J, Akkan D, et al. The prognostic importance of lung function in patients admitted with heart failure. Eur J Heart Fail 2010; 12: 685-691.

Almagro P, Soriano JB, Cabrera FJ, et al. Short- and medium-term prognosis in patients hospitalized for COPD exacerbation: the CODEX index. Chest 2014; 145: 972-980.

Miller J, Edwards LD, Agusti A, et al. Comorbidity, systemic inflammation and outcomes in the ECLIPSE cohort. Respir Med 2013; 107: 1376-1384.

Campo G, Napoli N, Serenelli C, et al. Impact of a recent hospitalization on treatment and prognosis of ST-segment elevation myocardial infarction. Int J Cardiol 2013; 167: 296-297.

Fabbri LM, Luppi F, Beghe B, et al. Complex chronic comorbidities of COPD. Eur Respir J 2008; 31: 204-212.

Bhatt SP, Dransfield MT. Chronic obstructive pulmonary disease and cardiovascular disease. Transl Res 2013; 162: 237-251.

Matamis D, Tsagourias M, Papathanasiou A, et al. Targeting occult heart failure in intensive care unit patients with acute chronic obstructive pulmonary disease exacerbation: effect on outcome and quality of life. J Crit Care 2014; 29: 315.e7-14.

MacDonald MI, Shafuddin E, King PT, et al. Cardiac dysfunction during exacerbations of chronic obstructive pulmonary disease. Lancet Respir Med 2016; 4: 138-148.

Lipworth B, Wedzicha J, Devereux G, et al. Beta-blockers in COPD: time for reappraisal. Eur Respir J 2016; 48 880-888.

Hoiseth AD, Neukamm A, Karlsson BD, et al. Elevated high-sensitivity cardiac troponin $\mathrm{T}$ is associated with increased mortality after acute exacerbation of chronic obstructive pulmonary disease. Thorax 2011; 66: 775-781. Singh S, Loke YK, Enright P, et al. Pro-arrhythmic and pro-ischaemic effects of inhaled anticholinergic medications. Thorax 2013; 68: 114-116.

Wilchesky M, Ernst P, Brophy JM, et al. Bronchodilator use and the risk of arrhythmia in COPD: part 2: reassessment in the larger Quebec cohort. Chest 2012; 142: 305-311.

Salpeter SR, Ormiston TM, Salpeter EE. Cardiovascular effects of beta-agonists in patients with asthma and COPD: a meta-analysis. Chest 2004; 125: 2309-2321.

Tashkin DP, Fabbri LM. Long-acting beta-agonists in the management of chronic obstructive pulmonary disease: current and future agents. Respir Res 2010; 11: 149.

Calverley P, Pauwels R, Vestbo J, et al. Combined salmeterol and fluticasone in the treatment of chronic obstructive pulmonary disease: a randomised controlled trial. Lancet 2003; 361: 449-456.

Szafranski W, Cukier A, Ramirez A, et al. Efficacy and safety of budesonide/formoterol in the management of chronic obstructive pulmonary disease. Eur Respir J 2003; 21: 74-81.

Calverley PM, Boonsawat W, Cseke Z, et al. Maintenance therapy with budesonide and formoterol in chronic obstructive pulmonary disease. Eur Respir J 2003; 22: 912-919.

Calverley PM, Anderson JA, Celli B, et al. Cardiovascular events in patients with COPD: TORCH study results. Thorax 2010; 65: 719-725.

Houben-Wilke S, Jorres RA, Bals R, et al. Peripheral artery disease and its clinical relevance in patients with COPD in the COSYCONET study. Am J Respir Crit Care Med 2017; 195: 189-197.

Divo M, Cote C, de Torres JP, et al. Comorbidities and risk of mortality in patients with chronic obstructive pulmonary disease. Am J Respir Crit Care Med 2012; 186: 155-161. tobacco-exposed cohort. Am J Respir Crit Care Med 2011; 183: 885-890. in patients with chronic obstructive pulmonary disease. Am J Respir Crit Care Med 2007; 176: 1208-1214.

Bolton CE, Cannings-John R, Edwards $\mathrm{PH}$, et al. What community measurements can be used to predict bone disease in patients with COPD? Respir Med 2008; 102: 651-657.

Bolton CE, Ionescu AA, Shiels KM, et al. Associated loss of fat-free mass and bone mineral density in chronic obstructive pulmonary disease. Am J Respir Crit Care Med 2004; 170: 1286-1293.

Jaramillo JD, Wilson C, Stinson DS, et al. Reduced bone density and vertebral fractures in smokers. Men and COPD patients at increased risk. Ann Am Thorac Soc 2015; 12: 648-656.

Jaramillo J, Wilson C, Stinson D, et al. Erratum: reduced bone density and vertebral fractures in smokers. Men and COPD patients at increased risk. Ann Am Thorac Soc 2015; 12: 1112.

Ng TP, Niti M, Tan WC, et al. Depressive symptoms and chronic obstructive pulmonary disease: effect on mortality, hospital readmission, symptom burden, functional status, and quality of life. Arch Intern Med 2007; 167: 60-67.

6 Eisner MD, Blanc PD, Yelin EH, et al. Influence of anxiety on health outcomes in COPD. Thorax 2010; 65: 229-234. 
de Torres JP, Bastarrika G, Wisnivesky JP, et al. Assessing the relationship between lung cancer risk and emphysema detected on low-dose CT of the chest. Chest 2007; 132: 1932-1938.

Wilson DO, Leader JK, Fuhrman CR, et al. Quantitative computed tomography analysis, airflow obstruction, and lung cancer in the pittsburgh lung screening study. J Thorac Oncol 2011; 6: 1200-1205.

Wilson DO, Weissfeld JL, Balkan A, et al. Association of radiographic emphysema and airflow obstruction with lung cancer. Am J Respir Crit Care Med 2008; 178: 738-744.

de-Torres JP, Wilson DO, Sanchez-Salcedo P, et al. Lung cancer in patients with chronic obstructive pulmonary disease. Development and validation of the COPD Lung Cancer Screening Score. Am J Respir Crit Care Med 2015; 191: 285-291.

Aberle DR, Adams AM, Berg CD, et al. Reduced lung-cancer mortality with low-dose computed tomographic screening. N Engl J Med 2011; 365: 395-409.

Infante M, Cavuto S, Lutman FR, et al. Long-term follow-up results of the DANTE trial, a randomized study of lung cancer screening with spiral computed tomography. Am J Respir Crit Care Med 2015; 191: 1166-1175.

Cebron Lipovec N, Beijers RJ, van den Borst B, et al. The prevalence of metabolic syndrome in chronic obstructive pulmonary disease: a systematic review. COPD 2016; 13: 399-406.

Martinez CH, Okajima Y, Murray S, et al. Impact of self-reported gastroesophageal reflux disease in subjects from COPDGene cohort. Respir Res 2014; 15: 62.

Ingebrigtsen TS, Marott JL, Vestbo J, et al. Gastro-esophageal reflux disease and exacerbations in chronic obstructive pulmonary disease. Respirology 2015; 20: 101-107.

Patel IS, Vlahos I, Wilkinson TM, et al. Bronchiectasis, exacerbation indices, and inflammation in chronic obstructive pulmonary disease. Am J Respir Crit Care Med 2004; 170: 400-407.

Shepard JW Jr, Garrison MW, Grither DA, et al. Relationship of ventricular ectopy to nocturnal oxygen desaturation in patients with chronic obstructive pulmonary disease. Am J Med 1985; 78: 28-34.

Bradley TD, Rutherford R, Grossman RF, et al. Role of daytime hypoxemia in the pathogenesis of right heart failure in the obstructive sleep apnea syndrome. Am Rev Respir Dis 1985; 131: 835-839.

apnea syndrome. Am Rev Respir Dis 1988; 138: 345-349. 